OPEN ACCESS

Edited by:

Xiao-Jun Ji,

Nanjing Tech University, China

Reviewed by:

Xiang Zou,

Southwest University, China

Xiulai Chen,

Jiangnan University, China

${ }^{*}$ Correspondence:

He Huang

Huangh@njnu.edu.cn

Hao Liu

liuhao@tust.edu.cn

Specialty section:

This article was submitted to

Industrial Biotechnology,

a section of the journal

Frontiers in Bioengineering and

Biotechnology

Received: 27 August 2021 Accepted: 16 September 2021 Published: 29 September 2021

Citation:

Wei Z, Xu Y, Xu Q, Cao W, Huang H and Liu H (2021) Microbial

Biosynthesis of L-Malic Acid and

Related Metabolic Engineering

Strategies: Advances and Prospects.

Front. Bioeng. Biotechnol. 9:765685.

doi: 10.3389/fbioe.2021.765685

\section{Microbial Biosynthesis of L-Malic Acid and Related Metabolic Engineering Strategies: Advances and Prospects}

\author{
Zhen Wei ${ }^{1}$, Yongxue $\mathrm{Xu}^{1}$, Qing $\mathrm{Xu}^{2}$, Wei Cao ${ }^{1,3}, \mathrm{He} \mathrm{Huang}^{2 *}$ and Hao Liu ${ }^{1,3 *}$ \\ ${ }^{1}$ MOE Key Laboratory of Industrial Fermentation Microbiology, College of Biotechnology, Tianjin University of Science \& \\ Technology, Tianjin, China, ${ }^{2}$ School of Food Science and Pharmaceutical Engineering, Nanjing Normal University, Nanjing, China, \\ ${ }^{3}$ Tianjin Engineering Research Center of Microbial Metabolism and Fermentation Process Control, Tianjin University of Science \& \\ Technology, Tianjin, China
}

Malic acid, a four-carbon dicarboxylic acid, is widely used in the food, chemical and medical industries. As an intermediate of the TCA cycle, malic acid is one of the most promising building block chemicals that can be produced from renewable sources. To date, chemical synthesis or enzymatic conversion of petrochemical feedstocks are still the dominant mode for malic acid production. However, with increasing concerns surrounding environmental issues in recent years, microbial fermentation for the production of L-malic acid was extensively explored as an eco-friendly production process. The rapid development of genetic engineering has resulted in some promising strains suitable for large-scale bio-based production of malic acid. This review offers a comprehensive overview of the most recent developments, including a spectrum of wild-type, mutant, laboratory-evolved and metabolically engineered microorganisms for malic acid production. The technological progress in the fermentative production of malic acid is presented. Metabolic engineering strategies for malic acid production in various microorganisms are particularly reviewed. Biosynthetic pathways, transport of malic acid, elimination of byproducts and enhancement of metabolic fluxes are discussed and compared as strategies for improving malic acid production, thus providing insights into the current state of malic acid production, as well as further research directions for more efficient and economical microbial malic acid production.

Keywords: L-malic acid, biosynthesis, Metabolic Engineering, fermentation, by-products

\section{INTRODUCTION}

L-malic acid is a ubiquitous dicarboxylic acid found in all organisms, but its name derives from the fact that it was first isolated from unripe apples in 1785 (Meek, 1975). In 1967, it was classified as a safe food-grade product by the U.S. Food and Drug Administration (FDA). Currently, malic acid is mainly used as an acidulant and flavor enhancer in the food and beverage industries. Due to its more intense acid taste and better taste retention compared with citric acid, L-malic acid is becoming one of the most widely used organic acidulants. In the pharmaceutical industry, L-malic acid is used to improve the absorption of drugs and is used in amino acid infusions for the treatment of liver dysfunction or high blood ammonia (Chi et al., 2014). A mixture of calcium citrate and calcium malate is a commonly used source of calcium for improved bone strength without increasing the risk of kidney stones (Thakker et al., 2015). Other commercial applications include metal cleaning, 
finishing, animal feed and chemical synthesis of biodegradable polymers, such as polymalic acid (PMA) (Goldberg et al., 2006; Dai et al., 2018). Malic acid was listed as one of the top twelve biobased building block chemicals by the US Department of Energy (Werpy and Petersen, 2004). The current global malic acid production capacity is estimated between 80,000 and 100,000 tons per year, while the annual market demand is estimated at over 200,000 tons, with a steadily rising market potential (Sauer et al., 2008; Zou et al., 2015).

The primary commercial production of malic acid is currently based on petrochemical routes, such as the hydration of maleic anhydride generated from the oxidation of benzene or butane at high temperature and high pressure, yielding a racemic mixture of D- and L-malic acid (Naude and Nicol, 2018). Malic acid has an asymmetric carbon and therefore it occurs in two isomers. Enantiopure L-malic acid is the physiological form present in all living organisms, ranging from bacteria to humans, while $\mathrm{D}$-malic acid is rare in nature and difficult to assimilate by humans, thus it is not applicable to very young infants and elderly people. In 1970, the U.S. FDA ruled that DL-malic acid could not be used as an additive in infant food. Enzymatic conversion is an alternative process for synthesis of L-malic acid, using either immobilized fumarate hydratase or whole cells (Brevibacterium ammoniagenes or Saccharomyces cerevisiae) containing the enzyme fumarate hydratase to catalyze the conversion of fumarate into malic acid (Chibata et al., 1987; Peleg et al., 1988; Knuf et al., 2014). However, the expensive purification of fumarate hydratase and difficult separation of L-malic acid from the unreacted substrate greatly increased the cost of L-malic acid production. In addition, substrates such as maleic anhydride or fumarate are derived from non-sustainable petroleum, and the upward trend in the cost of finite petroleum resources further hampered the expansion of the malic acid market (Goldberg et al., 2006; Liu et al., 2017a). With the increasingly severe challenges related to the depletion of fossil-based resources as well as environmental issues, ecofriendly sustainable microbial fermentative production of malic acid has been given more attention. A lot of progresses has been made in the development of engineered strains or processes in recent years.

The focus of this review concerns the latest progresses on malic acid production, biosynthetic pathways and metabolic engineering strategies. By summarizing the major progress in metabolic engineering strategies in various microbes, encompassing the enhancement of biosynthetic pathways, transportation systems and metabolic fluxes, as well as eliminating by-product pathway for improving malic acid production, this review aims to provide a valuable reference for future development of microbes as cell factories for industrial production of malic acid.

\section{MALIC ACID PRODUCTION USING WILD TYPE MICROORGANISMS}

As an intermediate of the TCA cycle, malic acid can be accumulated as a fermentation end-product by various microorganisms including filamentous fungi, yeasts, and bacteria. However, only a few wild-type filamentous fungi such as Aspergillus (Battat et al., 1991) and Penicillium (Wang et al., 2013; Khan et al., 2014) have the native ability to produce malic acid in large quantities from glucose and other carbon sources (Table 1).

Aspergillus species are well known strains for malic acid production. Aspergillus flavus was the first patented strain for malic acid production in 1963 (Abe et al., 1962). Through process optimization, A. flavus achieved a maximal malic acid titer of $113 \mathrm{~g} / \mathrm{L}$ in $190 \mathrm{~h}$ (Battat et al., 1991). However, it has never been applied for large-scale production of malic acid due to its production of carcinogenic aflatoxins during the fermentation process (Battat et al., 1991; Geiser et al., 1998). Aspergillus oryzae is generally regarded as safe (GRAS). Given its high similarity with A. flavus, A. oryzae NRRL 3488 was investigated for the production of malic acid. A titer of $30.27 \mathrm{~g} / \mathrm{L}$ malic acid was obtained with a yield of $0.98 \mathrm{~mol} / \mathrm{mol}$ under high glucose and nitrogen starvation conditions (Knuf et al., 2013). A. oryzae DSM1863 was used to produce malic acid from the waste substrate glycerol and the renewable carbon source xylose as, reaching product titers of 39.40 and $45.43 \mathrm{~g} / \mathrm{L}$, respectively (Ochsenreither et al., 2014). Aspergillus niger is a well-known industrial workhorse for the production of organic acids, and its application for malic acid production has received increasing attention in recent years. A. niger strains ATCC 9142 and ATCC 10577 were investigated for the production of malic acid from thin stillage, and achieved product titers of 17 and $19 \mathrm{~g} / \mathrm{L}$, respectively (West, 2011). When using crude glycerol as feedstock, A. niger ATCC 12486 could produce $23 \mathrm{~g} / \mathrm{L}$ malic acid after $192 \mathrm{~h}$ at $25^{\circ} \mathrm{C}$ (West, 2015).

Several Penicillium species such as $P$. viticola 152 and $P$. sclerotiorum $\mathrm{K} 302$ isolated from marine environments were reported to be good malic acid producers, respectively accumulating up to 131 and $71.67 \mathrm{~g} / \mathrm{L}$ L-malic acid from glucose in $10 \mathrm{~L}$ fermenters. The titer of $131 \mathrm{~g} / \mathrm{L}$ with a yield of $1.34 \mathrm{~mol} / \mathrm{mol}$ glucose and a productivity of $1.36 \mathrm{~g} / \mathrm{L} / \mathrm{h}$ represents the highest malic acid production achieved using Penicillium to date (Wang et al., 2013; Khan et al., 2014).

Yeasts such as $S$. cerevisiae are excellent platforms for the biological production of industrial chemicals and have also been investigated for fermentative malic acid production. Malic acid was detected as a by-product in the yeast fermentation process as early as 1924 (Yin et al., 2015). Afterwards, at least eight S. cerevisiae strains were tested in flasks to produce malic acid, but only two strains could synthesize more than $1 \mathrm{~g} / \mathrm{L}$ of malic acid in 7 days (Fatichenti et al., 1984). Zygosaccharomyces rouxii is an osmotolerant yeast associated with foods of low water activity. $Z$. rouxii V19 isolated from high-sugar fermented foods was able to produce $74.90 \mathrm{~g} / \mathrm{L}$ of malic acid with a yield of $0.52 \mathrm{~mol} / \mathrm{mol}$ from $193 \mathrm{~g} / \mathrm{L}$ glucose within 15 days under optimized conditions (Taing and Taing, 2007).

Some mushrooms also produce useful materials such as organic acids, and Schizophyllum commune IFO-4928 was able to produce $18 \mathrm{~g} / \mathrm{L}$ of malic acid from glucose under optimized conditions (Kawagoe et al., 1997). In addition, the yeast-like fungus Aureobasidium pullulans was identified as a proficient 
TABLE 1 | Malic acid production by wild type microorganisms.

\section{Microorganisms}

Aspergillu flavus ATCC 13697

Aspergillu flavus ATCC 13697

Aspergillu niger ATCC9142

Aspergillus niger ATCC10577

Aspergillus niger ATCC 12486

Aspergillus oryzae NRRL 3488

Aspergillus oryzae DSM1863

Aspergillus oryzae DSM1863

Aspergillus oryzae DSM1863

Penicillium viticola 152

Penicillium sclerotiorum K302

Saccharomyces cerevisiae

Saccharomyces cerevisiae

Schizophyllum commune

IFO-4928

Zygosaccharomyces rouxii V19

\begin{tabular}{lc} 
Substrates & Titer $(\mathbf{g} / \mathbf{L})$ \\
\hline Glucose & $58^{\mathrm{b}}$ \\
Glucose & $113^{\mathrm{c}}$ \\
Thin stillage & $17^{\mathrm{b}}$ \\
Thin stillage & $19^{\mathrm{b}}$ \\
Crude glycerol & $23^{\mathrm{b}}$ \\
Glucose & $30.27^{\mathrm{c}}$ \\
Glucose & $58.2^{\mathrm{b}}$ \\
Glycerol & $45.43^{\mathrm{b}}$ \\
Xylose & $39.40^{\mathrm{b}}$ \\
Glucose & $131^{\mathrm{c}}$ \\
Glucose & $71.67^{\mathrm{c}}$ \\
Glucose & $1^{\mathrm{b}}$ \\
Glucose & $2^{\mathrm{b}}$ \\
Glucose & $18^{\mathrm{c}}$
\end{tabular}

$74.90^{d}$

$\begin{array}{cc}\text { Yield }^{\mathbf{a}} \text { (mol/mol) } & \text { Productivity (g/L/h) } \\ 0.84 & 0.1 \\ 1.26 & 0.59 \\ 0.8(\mathrm{~g} / \mathrm{g}) & 0.09 \\ - & 0.10 \\ - & 0.12 \\ 0.98 & 0.89 \\ 0.76 & 0.16 \\ 0.37(\mathrm{~g} / \mathrm{g}) & 0.13 \\ 0.49(\mathrm{~g} / \mathrm{g}) & 0.11 \\ 1.34 & 1.36 \\ 0.93 & 1.00 \\ - & - \\ - & - \\ 0.48 & 0.18 \\ 0.52 & \\ & \end{array}$

Abe et al. (1962)

Battat et al. (1991)

West (2011)

West (2011)

West (2015)

Knuf et al. (2013)

Ochsenreither et al. (2014)

Ochsenreither et al. (2014)

Ochsenreither et al. (2014)

Khan et al. (2014)

Wang et al. (2013)

Fatichenti et al. (1984)

Schwartz and Radler (1988)

Kawagoe et al. (1997)

Taing and Taing (2007)

${ }^{a}$ Yields are given in mol malic acid per mol glucose unless otherwise indicated.

${ }^{b}$ Flask culture.

${ }^{c}$ Fermentor culture.

${ }^{d}$ Test tube - represents no value.

TABLE 2 | Malic acid production by mutants and evolutionarily engineered microorganisms.

\begin{tabular}{|c|c|c|c|c|c|}
\hline Microorganisms & Substrates & Titer (g/L) & Yield $(g / g)$ & Productivity (g/L/h) & References \\
\hline Aspergillus niger MTCC 281 & Crude glycerol & $77.38^{\mathrm{a}}$ & - & 0.40 & Iyyappan et al. (2018b) \\
\hline Aspergillus niger PJR1 & Crude glycerol & $83.23^{\mathrm{a}}$ & - & 0.43 & Iyyappan et al. (2018a) \\
\hline Aspergillus niger PJR1 & Crude glycerol & $92.64^{a}$ & - & 0.48 & Iyyappan et al. (2019b) \\
\hline Aspergillus oryzae FMME218-37 & Glucose & $95.2^{\mathrm{b}}$ & 0.54 & 0.57 & Ding et al. (2018) \\
\hline Monascus araneosus & Glucose & $27.9^{\mathrm{a}}$ & 0.37 & 0.23 & Lumyong and Tomita (1993) \\
\hline Rhizopus delemar & Corn straw & $120^{\mathrm{b}}$ & 0.96 & 2.03 & Li et al. (2014) \\
\hline Ustilago trichophora TZ1 & Crude glycerol & $195^{\mathrm{b}}$ & 0.43 & 0.74 & Zambanini et al. (2016a) \\
\hline Ustilago trichophora TZ1 & Crude glycerol & $196^{a}$ & 0.82 & 0.39 & Zambanini et al. (2016b) \\
\hline
\end{tabular}

${ }^{a}$ Flask culture.

${ }^{b}$ Fermentor culture - represents no value.

polymalic acid (PMA) producer, reaching a product titer of $47 \mathrm{~g} /$ $\mathrm{L}$ from glucose (Nagata et al., 1993). PMA is a linear anionic $\mathrm{C}_{4^{-}}$ polyester consisting of L-malic acid monomers. Recently, many researchers attempted to produce malic acid through the hydrolysis of PMA (Zou et al., 2013; Zou et al., 2015), and 144.2 g/L L-malic acid was obtained following purification and hydrolysis of $123.7 \mathrm{~g} / \mathrm{L}$ PMA, which was produced by fed-batch fermentation using cells immobilized in a fibrous-bed bioreactor (FBB). This process provided a novel approach for malic acid production (Zou et al., 2013).

\section{MALIC ACID PRODUCTION BY MUTANTS AND EVOLUTIONARILY ENGINEERED MICROORGANISMS}

Conventional mutagenesis based on soft X-rays, atmospheric and room temperature plasma (ARTP) or mutagenic chemicals was used to generate highly productive strains of Rhizopus delemar, A. oryzae and Monascus araneosus (Table 2). In addition, adaptive laboratory evolution was frequently used to improve microbial characteristics such as the ability to utilize non-preferred carbon sources for malic acid production (Zambanini et al., 2016b; Iyyappan et al., 2018b).

Using random mutagenesis and screening processes, a mutant of the zygomycete fungus $R$. delemar HF-121 was obtained that could produce more than $120 \mathrm{~g} / \mathrm{L}$ malic acid from corn straw hydrolysate in a pilot-scale fermenter within $60 \mathrm{~h}$. Moreover, it exhibited the highest malic acid productivity reported to date, reaching $2.03 \mathrm{~g} / \mathrm{L} / \mathrm{h}$. The high malic acid production from biomass hydrolysate highlights the prospect of large-scale industrial application of this strain ( $\mathrm{Li}$ et al., 2014). A. oryzae is an efficient malic acid-producing strain, and organic nitrogen is more favorable to the production of malic acid than inorganic nitrogen added in the fermentation culture. To meet the requirements of a low-cost nitrogen sources, Ding et al. (2018) constructed a library of mutants with $\left(\mathrm{NH}_{4}\right)_{2} \mathrm{SO}_{4}$ as the sole nitrogen source for L-malate production. Briefly, A. oryzae spores were firstly treated with atmospheric and room temperature plasma (ARTP) and ten mutants with relatively higher 
L-malate titers were selected out in the mutant library. The analysis of these 10 mutants revealed that the production of L-malate was positively related with the colony diameter $(D)$ and the specific surface area of unit volume (S2). Furtherly, the mutant with the highest L-malate production was treated with ${ }^{60} \mathrm{Co}-\gamma$ radials and DES solution. Using the above two parameters as the basis for selection, three strains with significantly increased L-malate production were finally obtained. The final titer and productivity of malic acid reached $95.2 \mathrm{~g} / \mathrm{L}$ and $0.57 \mathrm{~g} / \mathrm{L} / \mathrm{h}$ in a $7.5 \mathrm{~L}$ fermenter, which represents the highest level achieved to date in A. oryzae using an inorganic nitrogen source (Ding et al., 2018). In addition, an albino mutant was isolated following $\mathrm{N}$-methyl-N'-nitro-N-nitrosoguanidine treatment of Monascus araneosus AHU9087, which was able to produce $27.9 \mathrm{~g} / \mathrm{L}$ malic acid after 5 days at $37^{\circ} \mathrm{C}$ under aerobic conditions, compared with $20 \mathrm{~g} / \mathrm{L}$ produced by the parent strain (Lumyong and Tomita, 1993).

Geiser et al. (2014) screened 68 members of the family Ustilaginaceae for the production of organic acids, and found that many strains can accumulate organic acids, including malic acid (Geiser et al., 2014). Ustilago trichophora TZ1 was found to efficiently produce malic acid from glycerol. Following adaptive laboratory evolution and process optimization, the final malic acid titer, yield and overall productivity respectively reached $196 \mathrm{~g} / \mathrm{L}, 0.82 \mathrm{~g} / \mathrm{g}$ and $0.39 \mathrm{~g} / \mathrm{L} / \mathrm{h}$ in shake flasks (Zambanini et al., 2016b), as well as $195 \mathrm{~g} / \mathrm{L}, 0.43 \mathrm{~g} / \mathrm{g}, 0.74 \mathrm{~g} / \mathrm{L} / \mathrm{h}$ in a fedbatch bioreactor within $264 \mathrm{~h}$ (Zambanini et al., 2016a). However, the potential plant pathogenicity and limited genetic information are the major drawbacks of using Ustilago spp. in large-scale processes. Considering the important industrial value of $A$. niger, the mutant strain MTCC 281 with dual resistance to methanol and malic acid was obtained using an adaptation process spanning 22 weeks. The yield of malic acid from crude glycerol increased 4.45-fold compared with that of the parent strain, and the highest product titer reached $77.38 \mathrm{~g} / \mathrm{L}$ after $192 \mathrm{~h}$ at $25^{\circ} \mathrm{C}$ (Iyyappan et al., 2018b). In a different approach, the malic acid titer was increased to $83.23 \mathrm{~g} / \mathrm{L}$ by using morphologically controlled $A$. niger in the form of dispersed fungal mycelium in shake flask culture (Iyyappan et al., 2018a). After further process optimization, the maximal titer of malic acid reached up to 96.24 g/L (Iyyappan et al., 2019b).

\section{MALIC ACID PRODUCTION BY GENETICALLY ENGINEERED MICROORGANISMS USING METABOLIC ENGINEERING STRATEGIES}

As stated above, various wild-type and laboratory-evolved microorganisms have been investigated for fermentative production of malic acid, but the product yield or productivity is usually low and far from the requirements of large-scale industrial production (Table 1). With the increasing development of metabolic engineering and synthetic biology in the past decade, the engineering of biosynthetic pathways has become a viable approach for the construction of efficient microbial cell factories (Zhou et al., 2012; Choi et al., 2016; Chen et al., 2020). In recent years, many efficient L-malic acid production strains have been developed by redesign of biosynthetic pathways or transport systems and blocking the formation of byproducts (Table 3). Several metabolic pathways have been used to synthesize L-malic acid, including the reductive TCA (rTCA) pathway, the conversion of phosphoenolpyruvate into oxaloacetate, the tricarboxylic acid (TCA) cycle, the glyoxylate pathway, and direct one-step conversion of pyruvate into malic acid (Figure 1).

\section{Combined Enhancement of the rTCA Pathway and Malic Acid Transport}

The role of the rTCA pathway in L-malic acid production was first demonstrated in A. flavus using NMR-based metabolic flux analysis with $1-{ }^{13} \mathrm{C}$-laballed glucose as carbon source (Peleg et al., 1988). This pioneering study paved the way for targeted metabolic engineering towards efficient L-malic acid production. Subsequently, this pathway was also identified in $A$. niger, S. cerevisiae and $A$. oryzae using similar ${ }^{13} \mathrm{C} \mathrm{NMR}$ experiments (Peksel et al., 2002; Zelle et al., 2008; Knuf et al., 2014). These analyses clearly showed that rTCA is the predominant pathway for extracellular malic acid accumulation. The rTCA pathway takes place in the cytosol and involves the carboxylation of pyruvate to oxaloacetate, followed by the reduction of oxaloacetate to malic acid (Figure 1A). Pyruvate carboxylase (Pyc) is the first key enzyme in the rTCA pathway, catalyzing the ATP-dependent condensation of pyruvate and $\mathrm{CO}_{2}$ to form oxaloacetate (Goldberg et al., 2006; Dai et al., 2018). Generally, Pyc is situated in mitochondria of eukaryotic cells. However, the enzyme is localized exclusively in the cytosol in certain filamentous fungi and $S$. cerevisiae due to the lack of a mitochondrial-targeting peptide (van Urk et al., 1989; Bercovitz et al., 1990; Goldberg et al., 2006; Khan et al., 2017). Malic acid dehydrogenase (Mdh) is the second enzyme that catalyzes the $\mathrm{NAD}(\mathrm{H})$-dependent reversible conversion of malic acid into oxaloacetate. There are two forms of Mdh in eukaryotes, one of which is localized to the mitochondria and participates in the TCA cycle, while the other is localized to the cytoplasm and participates in the rTCA pathway (Goldberg et al., 2006). Additionally, a special form of malic acid dehydrogenase (Mdh3) found in S. cerevisiae was found to be localized in peroxisomes (Steffan and McAlister-Henn, 1992). During the acid production stage, the activity of malic acid dehydrogenase in A. flavus was found to be increased 6- to 10-fold compared with the growth stage, suggesting that Mdh is important for L-malic acid accumulation (Peleg et al., 1988; Battat et al., 1991). However, it was not clear which form of Mdh plays a major role in this process. Pyruvate is an important precursor for malic acid synthesis. If pyruvate is completely derived from the glycolytic pathway, then the ATP and redox reactions for malate synthesis via the rTCA pathway are balanced. In addition, $1 \mathrm{~mol}$ of $\mathrm{CO}_{2}$ is fixed in the carboxylation of $1 \mathrm{~mol}$ of pyruvate, which results in the maximal theoretical yield of malic acid being $2 \mathrm{~mol} / \mathrm{mol}$ of glucose (Zelle et al., 2008). Given its 
TABLE 3 | Malic acid production by metabolically engineered microorganisms.

\begin{tabular}{|c|c|c|c|c|c|c|}
\hline Microorganisms & $\begin{array}{l}\text { Titer } \\
\text { (g/L) }\end{array}$ & $\begin{array}{c}\text { Yield }^{\mathrm{a}} \\
\text { (mol/mol) }\end{array}$ & $\begin{array}{l}\text { Productivity } \\
\text { (g/L/h) }\end{array}$ & $\begin{array}{l}\text { Main by-products } \\
\text { (g/L) }\end{array}$ & $\begin{array}{l}\text { Genetic } \\
\text { modifications }\end{array}$ & References \\
\hline Aspergillus niger S1149 & $201.13^{\mathrm{b}}$ & 1.64 & 1.05 & Fumarate (1.50-1.80) & $\begin{array}{l}\Delta \text { oahA, } \Delta \text { cexA, OEpyc, OEmdh3, OE c4t318, } \\
\text { OEmstC, OEhxkA, OEpfkA, OEpkiA }\end{array}$ & Xu et al. (2020) \\
\hline Aspergillus niger S575 & $201.24^{\mathrm{b}}$ & 1.27 & 0.93 & Citrate (28.00) & $\Delta$ oahA, OEpyc, OEmdh3 and OE c4t318 & Xu et al. (2019) \\
\hline $\begin{array}{l}\text { Aspergillus oryzae } \\
2103 a-68\end{array}$ & $154^{\mathrm{b}}$ & 1.38 & 0.94 & $\begin{array}{l}\text { Succinate (13) and } \\
\text { citrate (6) }\end{array}$ & OEpyc, OEmdh3 and OEc4t318 & Brown et al. (2013) \\
\hline Aspergillus oryzae & $165^{\mathrm{b}}$ & 0.91 & 1.38 & $\begin{array}{l}\text { Succinate (18.7) and } \\
\text { fumarate }(4.0)\end{array}$ & $\begin{array}{l}\text { OEpyc, OEmdh, OEEcppc, OEEcpck, } \\
\text { OEc4t318, OESpMAE1 and OEpfk }\end{array}$ & Liu et al. (2017a) \\
\hline Aspergillus oryzae & $82.3^{\mathrm{C}}$ & $\begin{array}{c}0.82 \mathrm{~g} / \mathrm{g} \\
\text { (corn starch) }\end{array}$ & 1.18 & - & OEglaA, OEamyB, OEagdA and OEScfum 1 & Liu et al. (2017b) \\
\hline Aspergillus oryzae & $117.2^{\mathrm{C}}$ & $\begin{array}{l}0.9 \mathrm{~g} / \mathrm{g} \text { (corn } \\
\text { starch) }\end{array}$ & 1.17 & $\begin{array}{l}\text { Succinate }(3.8) \text { and } \\
\text { fumarate }(0.75)\end{array}$ & $\begin{array}{l}\text { OERopyc, OEicl1, OEicl2, OEmas, DRcs, } \\
\text { OESfc1p and OEnox }\end{array}$ & Liu et al. (2018) \\
\hline Aspergillus carbonarius & $32.0^{\mathrm{C}}$ & - & 0.15 & $\begin{array}{l}\text { Succinate }(16.0) \text { and } \\
\text { citrate }(5.2)\end{array}$ & OEdct & Yang et al. (2017b) \\
\hline Bacillus subtilis & $2.1^{\mathrm{c}}$ & 0.16 & 0.03 & Acetate (3.14) & $\Delta / d h, \mathrm{OEE} c p p c$ and OEScmdh & Mu and Wen (2013) \\
\hline Escherichia coli KJ071 & $69.1^{b}$ & 1.4 & 0.48 & $\begin{array}{l}\text { Succinate }(33.07) \text { and } \\
\text { pyruvate }(5.1)\end{array}$ & $\Delta / d h A, \Delta a d h E, \Delta a c k A, \Delta f o c A, \Delta p f B$ and $\Delta m g s A$ & $\begin{array}{l}\text { Jantama et al. } \\
\text { (2008) }\end{array}$ \\
\hline Escherichia coli XZ658 & $34^{b}$ & 1.42 & 0.47 & $\begin{array}{l}\text { Succinate }(1.18) \text { and } \\
\text { lactate }(1.08)\end{array}$ & $\begin{array}{l}\Delta / d h A, \Delta a c k A, \Delta a d h E, \Delta p f l B, \Delta m g s A, \Delta p o x B \\
\Delta f r d B C, \Delta s f c A, \Delta m a e B, \Delta f u m B \text { and } \Delta f u m A C\end{array}$ & Zhang et al. (2011) \\
\hline Escherichia coli & $36.05^{\mathrm{b}}$ & 0.74 & 0.60 & - & OEAfpyc, OEScms, OEcs, OEacn and OEicl & Gao et al. (2018) \\
\hline Escherichia coli F0931 & $21.65^{b}$ & 0.48 & 0.3 & $\begin{array}{l}\text { Pyruvate }(16.54) \text { and } \\
\text { succinate }(0.98)\end{array}$ & $\begin{array}{l}\Delta / d h A, \Delta p o x B, \Delta p f l B, \Delta p t a, \Delta a c k A, \Delta f r d B C \\
\Delta f u m A B C, \text { OEme and OEpos5 }\end{array}$ & Dong et al. (2017) \\
\hline Escherichia coli & - & 0.82 & - & fumarate $(-)$ & $\begin{array}{l}\Delta m d h, \Delta m q o, \Delta m a e A B, \Delta i c l R \text { arcA, OEppc and } \\
\text { OEgltA }\end{array}$ & Trichez et al. (2018) \\
\hline $\begin{array}{l}\text { Escherichia coli } \\
\text { GL2306 }\end{array}$ & $25.86^{c}$ & 0.53 & 0.36 & - & $\begin{array}{l}\Delta a d h E, \Delta a c k A, \Delta / d h A, \Delta p t s 1, \Delta p f l B, \Delta f o c A \\
\Delta m g s A, \text { OEEcpck and OEAsmdh }\end{array}$ & Guo et al. (2018) \\
\hline Escherichia coli & $17.83^{\mathrm{b}}$ & 1.3 & 0.38 & - & $\Delta / d h A, \Delta a d h E, \Delta i c / R, \Delta a c k, \Delta p t a$ and OEpyc & $\begin{array}{l}\text { Martinez et al. } \\
\text { (2018) }\end{array}$ \\
\hline Escherichia coli MA-11 & $5.90^{\mathrm{C}}$ & $\begin{array}{l}0.80 \mathrm{~g} / \mathrm{g} \\
\text { (xylose) }\end{array}$ & 0.08 & Glycolate (-) & $\begin{array}{l}\Delta m a e A, \Delta m a e B, \Delta m d h, \Delta f u m A C, \Delta f u m B \\
\text { OEdte, OEfucA, OEfuck, OEaldA, OEglcDEFB } \\
\text { and OEkatE }\end{array}$ & Li et al. (2018) \\
\hline Escherichia coli XL-1 & $12.08^{\mathrm{C}}$ & - & - & - & OEPykF and OESfCA & $\begin{array}{l}\text { Somasundaram } \\
\text { et al. (2018) }\end{array}$ \\
\hline $\begin{array}{l}\text { Myceliophthora } \\
\text { thermophile J207 }\end{array}$ & $181^{\mathrm{b}}$ & - (avicel) & - & Succinate (19.7) & OEAoc4t318 and OEAopyc & Li et al. (2019) \\
\hline Pichia pastoris & $42.28^{b}$ & 0.56 & 0.44 & Succinate (9.42) & OEpyc and OEmdh1 & Zhang et al. (2015) \\
\hline $\begin{array}{l}\text { Saccharomyces } \\
\text { cerevisiae } \mathrm{MDH}\end{array}$ & $11.8^{\mathrm{C}}$ & 0.13 & 0.38 & Citrate $(40.7)$ & OEmdh2 & Pines et al. (1997) \\
\hline $\begin{array}{l}\text { Saccharomyces } \\
\text { cerevisiae RWB525 }\end{array}$ & $59^{c}$ & 0.42 & 0.19 & $\begin{array}{l}\text { succinate }(8.0) \text { and } \\
\text { glycerol }(25.0)\end{array}$ & OEpyc2,OEmdh3 $\Delta S K L$ and OESpmae1 & Zelle et al. (2008) \\
\hline $\begin{array}{l}\text { Saccharomyces } \\
\text { cerevisiae RWB525 }\end{array}$ & $35.91^{\mathrm{b}}$ & 0.48 & - & $\begin{array}{l}\text { Pyruvate }(30.54) \text { and } \\
\text { succinate }(11.33)\end{array}$ & OEpyc2,OEmdh3 $\Delta S K L$ and OESpmae1 & Zelle et al. (2010) \\
\hline $\begin{array}{l}\text { Saccharomyces } \\
\text { cerevisiae }\end{array}$ & $30.25^{c}$ & 0.4 & 0.32 & Pyruvate $(30.75)$ & $\begin{array}{l}\text { OEAfpyc, OERopyc, OEAfmdh, OERomdh and } \\
\text { OESpMAE1 }\end{array}$ & Chen et al. (2017) \\
\hline Torulopsis glabrata & $8.5^{\mathrm{c}}$ & 0.19 & 0.18 & Pyruvate (-) & OERopyc, OERomdh and OESpMAE1 & Chen et al. (2013) \\
\hline $\begin{array}{l}\text { Thermobifida fusca } \\
\text { muC-16 }\end{array}$ & $62.76^{b}$ & $\begin{array}{l}0.63 \mathrm{~g} / \mathrm{g} \\
\text { (cellulose) }\end{array}$ & 0.51 & $\begin{array}{l}\text { Succinate }(2.40) \text { and } \\
\text { bytyrate }(11.1)\end{array}$ & OECgpyc & Deng et al. (2016) \\
\hline $\begin{array}{l}\text { Ustilago } \\
\text { trichophora TZ1 }\end{array}$ & $134^{\mathrm{b}}$ & $\begin{array}{l}0.42 \mathrm{~g} / \mathrm{g} \\
\text { (glycerol) }\end{array}$ & 0.56 & $\begin{array}{l}\text { Succinate (20) and } \\
\text { a-ketoglutarate (8) }\end{array}$ & $\begin{array}{l}\text { OEpyc, OEmdh1, OEmdh2, OEssu1 and } \\
\text { OEssu2 }\end{array}$ & $\begin{array}{l}\text { Zambanini et al. } \\
(2017)\end{array}$ \\
\hline
\end{tabular}

aYields are given in mol malate per mol glucose unless otherwise indicated.

${ }^{b}$ Fermentor culture.

${ }^{c}$ Flask culture - represents no value.

$O E$, overexpression; $D R$, down-regulation.

high theoretical yield and relative simplicity, the rTCA pathway has been extensively re-designed to improve malic acid production in yeasts and filamentous fungi (Table 3 ).

Several yeasts can accumulate L-malic acid through the rTCA pathway (Pines et al., 1996), and efforts have been made to improve malic acid production in S. cerevisiae (Zelle et al., 2008; Chen et al., 2017). The impact of individual and combined introduction of the native Pyc2, Mdh $3 \Delta S K L$ (deletion of the C-terminal peroxisomal targeting sequence) and malic acid transporter SpMael from Schizosaccharomyces pombe were evaluated in a $S$. cerevisiae TAM strain (van Maris et al., 2004; Zelle et al., 2008). Overexpression of $p y c 2$ alone and in combination with either $m d h 3 \Delta S K L$ or Spmae1 did not result in an increase of malic acid production, indicating that Pyc has a low degree of control over the rate of malic acid accumulation. By contrast, when malic acid dehydrogenase and a malic acid 

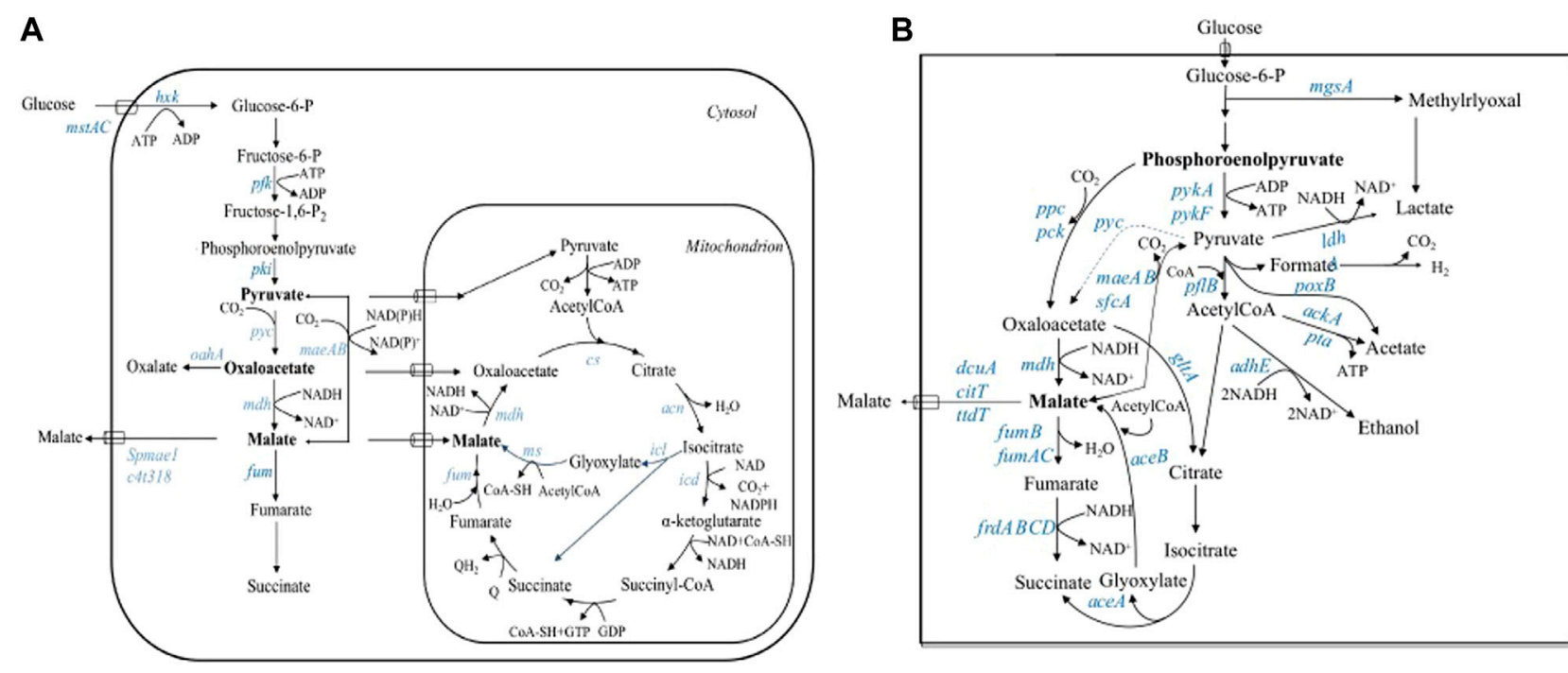

FIGURE 1 |Biosynthetic pathways of L-malic acid in eukaryotes (A) and prokaryotes (B). The dotted line indicates an exogenous pathway that does not exist in the natural strain. Enzyme-coding genes that were manipulated through genetic engineering are depicted in blue. Abbreviation: Panel (A): acn, aconitase; cs, citrate synthase; c4t318, malate transporter from Aspergillus oryzae; frd, fumarate reductase; fum, fumarase; $h x k$, hexokinase; icd, isocitrate dehydrogenase; icl, isocitrate lyase; mae $A B$, malic enzyme; $m d h$, malate dehydrogenase; $m s$, malate synthetase; $m s t A / C$, monosaccharide transporter; oahA, oxaloacetate acetylhydrolase; pfk, phosphofructokinase; pki, pyruvate kinase; pyc, pyruvate carboxylase; Spmae1, malate transporter from Schizosaccharomyces pombe. Panel (B): aceA, isocitrate lyase; aceB, malate synthase; ack $A$, acetate kinase; adhE, alcohol dehydrogenase; $c i t T$, citrate transporter; $d c u A$, dicarboxylate uptake transporter; frd $A B C D$, fumarate reductase; fumB/fumAC, fumarase; gltA, citrate synthase; IdhA, D-lactate dehydrogenase; mgs $A$, methylglyoxal synthase; pck, phosphoenolpyruvate carboxykinase; pflb, pyruvate formate-lyase; poxB, pyruvate oxidase; ppc, phosphoenolpyruvate carboxylase; pta, phosphate acetyltransferase; pyk, pyruvate kinase; sfc, succinate/ fumarate transporter; $t t d T$, tartrate transporter.

exporter were co-overexpressed, the control of malic acid production shifted towards Pyc. The highest malic acid yield $(0.42 \mathrm{~mol} / \mathrm{mol})$ and titer $(59 \mathrm{~g} / \mathrm{L})$ were obtained with the simultaneous introduction of all three modifications (Zelle et al., 2008). Under optimized conditions, the malic acid titer reached $35.91 \mathrm{~g} / \mathrm{L}$, with a yield of $0.48 \mathrm{~mol} / \mathrm{mol}$ in bioreactor cultures (Zelle et al., 2010). Chen et al. (2017) reconstructed the rTCA pathway in S. cerevisiae TAM for malic acid biosynthesis by combinatorial overexpression of Afpyc (from A. flavus), Romdh (from $R$. oryzae) and Spmae* (encoding a mutated Mae transporter resistant to ubiquitination) at different expression levels. The maximal titer of malic acid reached $30.25 \mathrm{~g} / \mathrm{L}$ during batch fermentation, which was lower than the previously reported $35.91 \mathrm{~g} / \mathrm{L}$ (Chen et al., 2017). In addition, Ropyc, Romdh and Spmae1 were heterologously overexpressed in Torulopsis glabrata to manipulate the carbon flux from pyruvate to malic acid, but the final titer of malic acid was only $8.5 \mathrm{~g} / \mathrm{L}$ (Chen et al., 2013). Pichia pastoris was engineered by overexpressing the native $p y c$ and $m d h 1$ genes, which resulted in a malic acid titer of $42.28 \mathrm{~g} / \mathrm{L}$ after $96 \mathrm{~h}$ (Zhang et al., 2015).

$U$. trichophora was engineered to accumulate high levels of malic acid by adaptive laboratory evolutionary as mentioned above. In order to further improve the yield of malic acid on glycerol, two malic acid dehydrogenases ( $m d h 1, m d h 2)$, and two malic acid transporters (ssu1, ssu2) were overexpressed in $U$. trichophora TZ1 (Zambanini et al., 2017), which increased the malic acid yield by up to $54 \%$, resulting in a titer of up to $120 \mathrm{~g} / \mathrm{L}$ in shake flasks. However, the final titer in bioreactor cultivation was dramatically decreased to $134 \mathrm{~g} / \mathrm{L}$, which was much lower than earlier reports (Zambanini et al., 2016a; Zambanini et al., 2016b). In addition, overexpression of $p y c$ alone resulted in lower or similar malic acid production compared to the reference strain (Zambanini et al., 2017).

In recent years, several attempts have been made to improve malic acid production by $A$. oryzae via genetic engineering. Overexpression of the endogenous transporter $\mathrm{C} 4 \mathrm{t} 318$ resulted in a greater than two-fold increase of L-malic acid productivity, while the additional overexpression of $p y c$ and $m d h 3$ in the rTCA pathway led to a further increase by about $27 \%$. The resulting strain overexpressing all three genes produced $154 \mathrm{~g} / \mathrm{L}$ malic acid with a yield of $1.38 \mathrm{~mol} / \mathrm{mol}$ and a productivity of $0.94 \mathrm{~g} / \mathrm{L} / \mathrm{h}$ (Brown et al., 2013). To further increase the production of malic acid, an oxaloacetate anaplerotic reaction was introduced to increase the supply of the oxaloacetate precursor by heterologous expression of the $p p c$ (encoding phosphoenolpyruvate carboxylase) and pck (phosphoenolpyruvate carboxykinase) genes from Escherichia. coli, which improved the malic acid titer by $38.3 \%$ (Liu et al., 2017a). After further overexpression of the endogenous 6phosphofructokinase $(p f k)$ to strengthen the metabolic flux from glucose, the malic acid titer was increased to $165 \mathrm{~g} / \mathrm{L}$, with a yield and productivity of $0.68 \mathrm{~g} / \mathrm{g}$ and $1.38 \mathrm{~g} / \mathrm{L} / \mathrm{h}$, respectively, which represents the highest levels of malic acid production in A. oryzae reported to date (Liu et al., 2017a).

Myceliophthora thermophila can efficiently utilize cellulose and hemicellulose, which makes it a promising candidate for 
the production of $\mathrm{C}_{4}$-dicarboxylic acids. Both the $c 4 t 318$ and $p y c$ genes from $A$. oryzae were heterologously overexpressed in $M$. thermophila, and the resulting strain JG207 was able to produce $65.4 \mathrm{~g} / \mathrm{L}$ malic acid from $75 \mathrm{~g} / \mathrm{L}$ Avicel ${ }^{\circledR}$ in shake flask cultures (Li et al., 2019). With Avicel ${ }^{\circledR}$ and corncob as the feedstock, 181 and $105 \mathrm{~g} / \mathrm{L}$ of malic acid were produced in fed-batch fermentation, respectively. Transcriptional profiling analysis indicated that the cytosolic rTCA pathway was the main synthetic route of malic acid in strain JG207 grown on cellulose. After $p p c$ gene form $E$. coli and the native cytoplasmic $m d h$ were co-overexpressed, the malic acid titer increased to $72.4 \mathrm{~g} / \mathrm{L}$, with a yield of $0.96 \mathrm{~g} / \mathrm{g}$, which was higher than that of the parental strain $(0.88 \mathrm{~g} / \mathrm{g})$. To increase the supply of $\mathrm{CO}_{2}$ in the cytoplasm, a $\mathrm{CO}_{2}$ concentration pathway was constructed by integrating $\operatorname{bicA}\left(\mathrm{HCO}_{3}{ }^{-}\right.$transporter gene) and ca (carbonic anhydrase gene) from Synechococcus sp. PCC7002 into the loci of $p d c$ (encoding pyruvate decarboxylase) and $l d h$ (acetate dehydrogenase), respectively, thereby reducing competing pyruvate consumption at the same time. The resulting strain displayed a further $15 \%$ increase of malic acid production, with a titer of $83.3 \mathrm{~g} / \mathrm{L}$ and a yield of $1.11 \mathrm{~g} / \mathrm{g}$ in shake flasks with Avicel $^{\circledR}$ as the substrate (Li et al., 2019).

Most recently, A. niger has been successfully engineered for fermentative production of malic acid by deleting the oxaloacetate acetylhydrolase gene (oahA) and overexpressing the endogenous rTCA pathway genes $p y c$ and $m d h 3$, combined with the insertion of the malic acid transporter gene c4t318 from $A$. oryzae. The malic acid titer of the engineered strain S575 was increased over 5-fold compared with the wildtype strain, reaching $120.38 \mathrm{~g} / \mathrm{L}$ in shake-flask culture. Moreover, this titer was increased to $201.24 \mathrm{~g} / \mathrm{L}$ in fed-batch fermentation, with an overall productivity of $0.93 \mathrm{~g} / \mathrm{L} / \mathrm{h}$, and yield of $1.27 \mathrm{~mol} /$ mol glucose (Xu et al., 2019). In A. niger, oxaloacetate is the common precursor of oxalic acid and malic acid biosynthesis through the rTCA pathway (Figure 1A). Deletion of oahA blocked the oxalic acid synthesis, resulting in a $40 \%$ increase of the malic acid titer. Further enhancement of the rTCA pathway and overexpression of the malic acid transporter C4t318 led to an additional 4 -fold increase of the product titer. The resulting titer of $201.24 \mathrm{~g} / \mathrm{L}$ is the highest level of malic acid production reported to date, and is close to the requirements of industrial production (Xu et al., 2019). Therefore, the strategy of combinational enhancement of the rTCA pathway and malic acid transport is the most commonly employed and remarkably effective was to improve malic acid production in yeasts and filamentous fungi. In addition, increasing the supply of precursors such as oxaloacetate and $\mathrm{CO}_{2}$ is also important for further improvement of malic acid production (Liu et al., 2017a; Li et al., 2019).

\section{Engineering the Non-Oxidative Pathway for Malic Acid Production}

Different from filamentous fungi and yeasts, in which the rTCA pathway was engineered to improve malic acid production, boosting the conversion of phosphoenolpyruvate (PEP) into oxaloacetate by overexpressing $p p c$ or $p c k$, followed by reduction to malic acid, is a common strategy for the production of malic acid in E. coli, which has no pyruvate carboxylase ( $\mathrm{Li}$ Q. et al., 2016) (Figure 1B). Zhang et al. (2011) confirmed that disruption of pck in E. coli XZ658 led to a dramatic decrease of malic acid production (Zhang et al., 2011). Although E. coli has been genetically modified for L-malate production, the wild-type didn't exhibit a potential in L-malate secretion (Kövilein et al., 2020). Similarly, no malic acid was produced by the host $E$. coli WGS-10. By strengthening the supply of the precursor substance oxaloacetate by homologous or heterogenous overexpression of $p c k A$, L-malate titers increased to $1.42 \mathrm{~g} / \mathrm{L}$ and $9.25 \mathrm{~g} / \mathrm{L}$, respectively (Moon et al., 2008). More recently, Guo et al. (2018) constructed the dual regulation strain E. coli GL2306 by first deleting multiple genes ( $a d h E$, ack $A$, ldhA, $p t s 1, p f l B, f o c A$ and $m g s A$ ) to increase the PEP pool, and then cooverexpressing Ecpck and Asmdh from Actinobacillus succinogenes to reconstruct the malic acid biosynthesis pathway, which was targeted to the periplasm and cytoplasm using appropriate signal peptides. The final engineered strain GL2306 produced $25.86 \mathrm{~g} / \mathrm{L}$ malic acid with a yield of $0.53 \mathrm{~mol} /$ mol in a 5-L two-stage fed-batch process (Guo et al., 2018). B. subtilis was also metabolically engineered to produce malic acid by heterologous overexpression of $p p c$ (from E. coli) and $m d h 2$ (from $S$. cerevisiae) and deletion of $l d h$. The resulting strain produced a low titer of malic acid $(2.01 \mathrm{~g} / \mathrm{L})$, but it represents the first engineered $B$. subtilis for malic acid production ( $\mathrm{Mu}$ and Wen, 2013). Additionally, the impact of heterologous expression of Pyc for malic acid production has also been investigated in prokaryotes such as E. coli and Thermobifida fusca. Several metabolically engineered E. coli strains were constructed by single, double and triple deletion of fumABC in the background of a $\Delta l d h A / \triangle a d h E$ double mutant, together with the overexpression of $p y c$ from Lactococcus lactis. Only the fumAC and the triple fum $A B C$ deletion strains accumulated malic acid as the main C4-dicarboxylic acid product with a yield of $0.61-0.67 \mathrm{~mol} / \mathrm{mol}$ glucose (Martinez et al., 2018). Overexpression of an exogenous pyc gene from Corynebacterium glutamicum in T. fusca muC resulted in a $47.9 \%$ increase of the malic acid yield compared to the parental strain. The final strain T. fusca muC-16 was cultured on glucose and milled corn stover, which resulted in malic acid titers of 62.76 and $21.47 \mathrm{~g} / \mathrm{L}$, respectively. These studies were conducted in batch fermentation under low oxygen conditions, and butyrate was accumulated as the main by-product (Deng et al., 2016).

\section{Engineering the TCA Cycle for Malic Acid Production}

Malic acid is an intrinsic intermediate of the TCA cycle, in which oxaloacetate and acetyl-coenzyme A (acetyl-CoA) are condensed to citrate followed by several oxidative reactions to form malic acid. Because two $\mathrm{CO}_{2}$ molecules are released during the oxidation of citrate to malic acid, the maximal theoretical yield is limited to $1 \mathrm{~mol} / \mathrm{mol}$ glucose. Recently, Trichez et al. (2018) engineered $E$. coli for malic acid production via the TCA cycle, and found that achieving a significant yield of malic acid $(0.82 \mathrm{~mol} / \mathrm{mol})$ required at least the simultaneous deletion of all malic enzymes and dehydrogenases $(\Delta m d h, \Delta m q o, \Delta m a e A B$, 
$\triangle i c l R$ and $\triangle a r c A$ ), with the concomitant expression of the malic acid-insensitive PEP carboxylase mutant $\mathrm{Ppc}^{\mathrm{K} 620 \mathrm{~S}}$ and NADHinsensitive citrate synthase mutant $\mathrm{GltA}^{\mathrm{R} 164 \mathrm{~L}}$. However, metabolic flux analysis based on ${ }^{13} \mathrm{C}$-labeled glucose indicated that the malic acid-producing strains had a very high flux through the glyoxylate shunt, with almost no flux passing through the isocitrate dehydrogenase (Icd) reaction. Generally, the TCA cycle oxidizes citrate into malic acid through a series of reactions under aerobic conditions, yet the highest malic acid production was achieved anaerobically (Trichez et al., 2018). In addition, although malic acid production through the TCA cycle can be achieved in E. coli, the fumarate by-product was also significantly accumulated, which makes this strategy unattractive compared to non-oxidative pathways (Trichez et al., 2018).

Liu et al. (2018) engineered the TCA cycle for malic acid production in $A$. oryzae by simultaneously overexpressing citrate synthase (CIS), isocitrate dehydrogenase (ISD), a-oxoglutarate dehydrogenase (OXD) and aconitate hydratase (ACH). However, the enhanced oxidative TCA cycle was unfavorable for malic acid synthesis, and actually decreased the malic acid titer from 95.1 to $83.7 \mathrm{~g} / \mathrm{L}$ in corn starch culture. Conversely, appropriately downregulating the oxidative branch of the TCA cycle increased the carbon flux toward the rTCA pathway (Liu et al., 2018).

\section{Engineering the Glyoxylate Metabolism for Malic Acid Production}

In bacteria and certain species of fungi, glyoxylate metabolism proceeds either via the glyoxylate cycle or the noncyclic glyoxylate shunt. Isocitrate lyase (Icl) and malic acid synthetase (Ms) are the two crucial enzymes in this pathway. Isocitrate lyase converts the isocitrate formed in the TCA cycle into succinate and glyoxylate, followed by the condensation of glyoxylate with acetyl CoA by malic acid synthetase (Iyyappan et al., 2019a). The glyoxylate shunt has not been found to be reversible to date (Mainguet et al., 2013). However, the synthesis of acetyl-CoA from pyruvate is accompanied by carbon loss due to $\mathrm{CO}_{2}$ release, which constrains the maximal theoretical malic acid yield in the glyoxylate cycle to $1 \mathrm{~mol} / \mathrm{mol}$ glucose. If oxaloacetate is replenished by the carboxylation of pyruvate, the glyoxylate pathway is noncyclic, and the maximal malic acid yield increases to $1.33 \mathrm{~mol} / \mathrm{mol}$.

Recent studies have focused on the glyoxylate pathway for malic acid production. Although the overexpression of Icl in $A$. niger did not increase the production of malic acid (Meijer et al., 2009), the co-overexpression of Icl and Ms in A. oryzae increased the malic acid titer from 95.1 L to $99.8 \mathrm{~g} / \mathrm{L}$ (Liu et al., 2018). To test the possibility of enhancing the malic acid yield of $E$. coli in aerobic fermentation based on the noncyclic glyoxylate shunt, Gao et al. (2018) recently established a five-enzyme (Pyc, Cs, Acn, Icl, Ms) cascade by integrating in vitro modular engineering with in vivo multiplexed CRISPRi tuning. The final strain E. coli B0013-47 exhibited a 2.3-fold higher malic acid titer than the parent, reaching $36 \mathrm{~g} / \mathrm{L}$ with a yield of $0.74 \mathrm{~mol} / \mathrm{mol}$ glucose in fed-batch fermentation. The advantage of this strategy is that the disbalance between different modules such as the accumulation of citrate and a-ketoglutarate can be solved using CRISPRi (Gao et al., 2018).

\section{Constructing a One-Step Pathway for Malic Acid Production}

The one-step pathway involves the direct conversion of pyruvate into malic acid catalyzed by malic enzyme using $\mathrm{NAD}^{+} / \mathrm{NADP}^{+}$ as cofactor. Since there are no intermediates, carbon loss is minimized and the substrate transmission rate is improved in this pathway, which makes it possible to maximize the carbon flux for malic acid synthesis (Dong et al., 2017). The one-step conversion of pyruvate from glycolysis into malic acid via the malic enzyme has a theoretical yield of $2 \mathrm{~mol} / \mathrm{mol}$ (Dong et al., 2017). However, malic enzyme catalyzes the reversible oxidative decarboxylation of malic acid into pyruvate and $\mathrm{CO}_{2}$, and the forward reaction (malic acid into pyruvate) is thermodynamically favorable due to the enzyme's low affinity for pyruvate (Zhang et al., 2011).

In order to push the reversible carboxylation of pyruvate for efficient L-malic acid production, an $\mathrm{NADP}^{+}$-dependent malic enzyme from Arabidopsis thaliana (NADP-ME $\mathrm{M}_{2}$ ) with higher affinity for pyruvate was selected and modified by site-directed mutagenesis. The best mutant $\mathrm{ME}_{2}(\mathrm{C} 490 \mathrm{~S})$ showed a $56 \%$ improvement of malate synthesis activity, and its introduction into E. coli F0501 ( $\Delta l d h A, \Delta p o x B, \Delta p f l B, \Delta p t a$ and $\Delta a c k A)$, decreased pyruvate accumulation and the titer of L-malate increased by $83 \%$. Further inactivation of succinate synthesis genes enhanced the malic acid titer to $7.78 \mathrm{~g} / \mathrm{L}$ and overexpression of $S$. cerevisiae $\mathrm{NADH}$ kinase (Pos5), which phosphorylates $\mathrm{NADH}$ to generate $\mathrm{NADPH}$, resulted in the maximal titer of $21.65 \mathrm{~g} / \mathrm{L}$ with a yield of in a $0.48 \mathrm{~mol} / \mathrm{mol}$ in a $5 \mathrm{~L}$ bioreactor fermentation. However, $16.54 \mathrm{~g} / \mathrm{L}$ pyruvate was still accumulated as the main by-product. This study demonstrated the potential utility of the one-step pathway for efficient L-malic acid production, whereby elevating NADPH levels is a key factor (Dong et al., 2017). More recently, a recombinant expression strategy was employed to co-localize the native pyruvate kinase $(\mathrm{PykF})$ and malic enzyme $(\mathrm{SfcA})$ by forming an enzyme scaffold complex in E. coli. The close colocalization of PykF and SfcA can increase the pathway flux from pyruvate to malic acid in the one-step pathway. In a flask culture, the recombinant strain harboring the scaffold complex produced a maximal malic acid titer of $5.72 \mathrm{~g} / \mathrm{L}$ from $10 \mathrm{~g} / \mathrm{L}$ glucose, which was significantly increased 2.1 -fold. In a 5 -L bioreactor, the malic acid production reached $12.08 \mathrm{~g} / \mathrm{L}$ (Somasundaram et al., 2018).

\section{Malic Acid Export}

An important aspect of organic acid production in microbial cell factories is the export of the product across the cell membrane into the culture supernatant (Sauer et al., 2008). Export of products can not only reduce the toxicity of intracellular product accumulation, but also increase the product yield by relieving negative feedback regulation. As stated above, enhancing the capacity of L-malic acid excretion by genetic modification is a highly effective strategy that has been widely employed in filamentous fungi and yeasts (Zelle et al., 2008; 
Brown et al., 2013; Zambanini et al., 2017; Li et al., 2019; Xu et al., 2019). The Mael malic acid transporter from S. pombe was overexpressed in several fungi to improve their malic acid production as mentioned above (Zelle et al., 2008; Chen et al., 2013; Liu et al., 2017a; Chen et al., 2017). Notably, its expression in S. cerevisiae increaseed malic acid production threefold (Zelle et al., 2008). Additionally, the SpMae1 homologs C4t318 and AcDct were identified in A. oryzae and A. carbonarius, respectively (Brown et al., 2013; Yang et al., 2017a). Although the mechanism of these malic acid export proteins has been partly elucidated, there is still limited information on the control of the metabolic flux towards malic acid through manipulation of malic acid transporters in microbial cell factories. Originally, SpMae1 was annotated as a member of the TDT family and was believed to use the proton motive force to transport malate, succinate and malonate in S. pombe (Grobler et al., 1995). Now it is clear that AcDct and SpMael belong to the voltage-gated anion channel family SLAC1 (slow-anion channel), which do not use protons, $\mathrm{Na}^{+}$, or ATP (Darbani et al., 2019). Such transporters offer a tremendous advantage for fermentative organic acid production, allowing a higher overall product yield due to their lower energy requirements. More recently, we tested the impact of deleting five putative C4-dicarboxylate transporters (dct1, dct2, dct3, dct4 and $d c t 5$ ) in A. niger, and found that Dctl (ASPNIDRAFT_193,984) was the key malic acid exporter. Deletion of Dct1 resulted in almost complete absence of malic acid accumulation, while its overexpression significantly improved the malic acid yield (Cao et al., 2020).

Transporter engineering to improve the malic acid production of bacteria is rarely reported. The three transporters DcuA, CitT, and $\mathrm{TtdT}$ were identified as the major malic acid export proteins of E. coli (Kurgan et al., 2019). Inactivation of each one significantly decreased the malic acid titer, but the overexpression of each one resulted in no improvement of malic acid production (Trichez et al., 2018; Kurgan et al., 2019). This suggests that any of the malic acid transporters is sufficient for current production metrics, or there is a limitation of counter ions for the current transport mechanism. Moreover, transporter redundancy is a common phenomenon in organic acids export in E. coli. For instance, cells were still capable of producing $30 \%$ of the final malic acid titer of the reference strain XZ658 after the simultaneous deletion of $d c u A$, cit $T$, and $t t d T$ (Kurgan et al., 2019).

\section{Elimination of By-Product Accumulation}

Microbial production of malic acid is normally accompanied by the accumulation of high levels of various by-products, mainly including other organic acids (Table 3). For instance, E. coli KJ071 and W3110 respectively accumulated $33.07 \mathrm{~g} / \mathrm{L}$ succinate and $16.54 \mathrm{~g} / \mathrm{L}$ pyruvate (Jantama et al., 2008; Dong et al., 2017), while $S$. cerevisiae produced more than $30 \mathrm{~g} / \mathrm{L}$ pyruvate in the process for malic acid fermentation (Zelle et al., 2008). The concentration of these by-products was more than half the concentration of malic acid. Similarly, despite the high titers of malic acid achieved using filamentous fungi such as A. oryzae and $M$. thermophila, they also produced around $19 \mathrm{~g} / \mathrm{L}$ succinate at the same time (Liu et al., 2017a; Li et al., 2019). The biosynthesis of these by-products not only consumes carbon sources, thereby reducing the yield of the target product, but also increases the cost of downstream product separation and purification. As a consequence, inhibition of by-product formation in various fermentation processes has also been the focus of research.

E. coli cannot accumulate malic acid under normal circumstances (Martinez et al., 2018), but it produces high levels of acetate, lactate, ethanol and formate during glucose fermentation. Blocking the synthesis of these by-products is vital for engineering $E$. coli to accumulate high levels of malic acid. Thus, genetic modification of E. coli usually starts by deleting genes encoding key enzymes of competing pathways (Jantama et al., 2008; Zhang et al., 2011; Guo et al., 2018). Following the deletion of ldhA, adhE, ackA, focA, pflB and $m g s A$ in the evolved strain E. coli $\mathrm{C}$, the highest malic acid titer of the resulting strain KJ071 reached $69.14 \mathrm{~g} / \mathrm{L}$. However, the strain also accumulated $33.07 \mathrm{~g} / \mathrm{L}$ succinate (Jantama et al., 2008). The succinate-producing E. coli KJ073 ( $\Delta l d h A, \Delta a d h E, \Delta a c k A$, $\triangle f o c A, \Delta p f l B, \Delta m g s A$ and $\Delta p o x B$ ) was also modified to produce malic acid (Zhang et al., 2011). Inactivation of fumarate reductase $(\triangle f r d B C)$ eliminated over $90 \%$ of succinate production, but also led to an increase of pyruvate and decrease of acetate. After deletion of malic enzyme genes ( $s f A$ and maeB), pyruvate production was almost completely eliminated and malic acid production was further increased. Additional deletion of the three fumarase genes (fum $A B C$ ) increased the malic acid titer 4 -fold but caused a large and unexpected increase of lactate production. The final strain XZ658 produced $34 \mathrm{~g} / \mathrm{L}$ malic acid with a yield of $1.42 \mathrm{~mol} / \mathrm{mol}$ glucose, achieving an over 500-fold increase of the malate titer using a two-stage process (aerobic cell growth and anaerobic malic acid production). At the same time, the byproduct titers of succinic, lactic and acetic acid were dramatically decreased to $1.18,1.08$ and $0.48 \mathrm{~g} / \mathrm{L}$, respectively (Zhang et al., 2011). In E. coli, all these by-products are derived from pyruvate, and inhibition of pyruvate formation is an effective strategy for reducing by-product biosynthesis and PEP consumption (Zhu and Tang, 2017). For instance, deletion of pyruvate kinase ( $p y k A$ or $p y k F$ ) reduced lactate production by over $90 \%$ (Zhang et al., 2011). However, pyruvate is also an important intermediate in the synthesis pathway of malic acid (Zelle et al., 2010; Dong et al., 2017), and disruption of the key genes in the relevant pathways would also reduce the malic acid production. Thus, blocking pyruvate secretion may be more effective in this situation. Conceptually similar strategies were proven successful in the metabolic engineering of host strains to produce L-arginine and 5-aminovalerate (Park et al., 2014; Li Z. et al., 2016).

Two strategies were developed to reduce succinate accumulation in A. oryzae (Liu et al., 2018). The first strategy is based on the fact that the intracellular succinate and fumarate are mainly present in the cytosol and mitochondria. The dicarboxylate carrier Sfclp from S. cerevisiae is an antiporter that imports succinate into mitochondria and exports fumarate into the cytosol. When it was overexpressed, the succinate byproduct titer was decreased, while malic acid production was increased due to more fumarate being converted into malic acid in the cytosol. This strategy might also be suitable for the 
metabolic engineering of other fungi or yeasts to weaken the accumulation of succinate. Given that excess supply of NADH may accelerate succinate synthesis, the second strategy is based on tuning the intracellular redox potential to reduce the NADH/ $\mathrm{NAD}^{+}$ratio by overexpressing the NADH oxidase (NOX) from Streptococcus lactis. To the end, L-malate titer of the engineered A. oryzae strain finally increased to $117.2 \mathrm{~g} / \mathrm{L}$ and the by-product succinate titer decreased to $3.8 \mathrm{~g} / \mathrm{L}$. However, a very low level of NADH was unfavorable for malic acid synthesis (Liu et al., 2018).

Oxalate and citrate are the main by-products accompanying malic acid production in $A$. niger as mentioned above (Xu et al., 2019). Oxalate can be completely eliminated by deletion of $o a h A$, but the resulting strain still accumulated $28.00 \mathrm{~g} / \mathrm{L}$ of citric acid in fed-batch fermentation (Xu et al., 2019). Hence, the accumulation of citrate is one of the main unaddressed issues in the application of $A$. niger for malic acid production. In order to eliminate or reduce the synthesis of citrate, we recently explored the effects of two different potential targets, the global regulator LaeA and the citric acid transporter CexA, which respectively affect citric acid production and transport (Niu et al., 2015; Steiger et al., 2019), in the malic acid-producing strain A. niger S575. It was found that disruption of cexA could abolish the accumulation of citric acid (Xu et al., 2020). This strategy might also be suitable for the metabolic engineering other fungi such as A. carbonarius to eliminate the accumulation of citrate. The strategy of deleting by-product exporters to block their extracellular accumulation may not be applicable to other $\mathrm{C}_{4}$-dicarboxylic acids such as succinate and fumarate. Firstly, no specific fumarate or succinate transporter was identified to date. Moreover, the known $\mathrm{C}_{4^{-}}$ dicarboxylate transporters such as SpMae1, AcDct and DctA are generally responsible for the export of several $\mathrm{C}_{4}$-dicarboxylic acids, including malic acid (Janausch et al., 2002; Valentini et al., 2011; Yang et al., 2017a; Darbani et al., 2019). Hence, enhancing these exporters is necessary for improving malic acid production. Additionally, agitation rate, nitrogen, Fe (II) ion and phosphate concentrations were also found to be impact factors of L-malate and othe C4-dicarboxylate accumulations in a 16-L stirred fermentor by Aspergillus flavus (Battat E. et al., 1991).

In brief, there are three potential strategies of eliminations of the byproducts: 1) deleting or weakening competing pathways for biosynthesis or transport process, 2) mining more efficient key enzymes at the metabolic node for L-malate biosynthesis, 3) optimizing fermentation process parameters.

\section{Enhancing Metabolic Fluxes to Improve the Production of L-Malic Acid}

Phosphofructokinase-1 (Pfk1), which catalyzes the irreversible ATP-dependent phosphorylation of D-fructose 6-phosphate to fructose 1,6-bisphosphate, is the rate-limiting enzyme of the glycolytic pathway. Its activity is affected by a series of intracellular compounds such as citrate, ATP, cAMP, ammonia or trace metals ( $\mathrm{Mn}$ and $\mathrm{Mg}$ ) (Habison et al., 1983; Arts et al., 1987). Previously, it was considered to be a major regulatory enzyme for metabolic flux control during the production of citric acid in A. niger (Yang et al., 2017b). Overexpression of a truncated Pfk1, which is not inhibited by intracellular citrate, resulted in enhanced citric acid production in A. niger (Ruijter et al., 1997; Capuder et al., 2009). Increasing the metabolic flux in the glycolytic pathway to improved citric acid production provided a good basis for the production of malic acid when combined with other genetic modifications in other strains. Guided by transcription analysis of the expression profiles of key genes related to L-malic acid synthesis, Pfk was identified as a potential rate-limiting enzyme for L-malate production in a malic acid-producing strain of $A$. oryzae. Overexpression of $p f k$ under the control of the strong and inducible sodM promoter twsited the repression of $p f k$ expression probablely caused by malate accumulation. Based on the above changes, the L-malate titer increased from 89.5 to $93.2 \mathrm{~g} / \mathrm{L}$ in shake flasks (Liu et al., 2017a).

The engineered malic acid-producing strain M. thermophila JG207 is distinct from A. oryzae because it does not show changes in the transcription levels of the glycolytic pathway genes compared with the wild type when grown on glucose, in spite of more efficient substrate utilization. However, strain JG207 showed markedly higher expression levels of multiple sugar transporter genes with either glucose or cellulose as substrate. Further enhancing glucose transportation by heterologous expression of the low-affinity glucose transporter GLT-1 from Neurospora crassa efficiently improved the conversion of substrates, and also increased malic acid production ( $\mathrm{Li}$ et al., 2019).

In addition to Pfk, there are two other irreversible steps in the glycolytic pathway, phosphorylation of glucose catalyzed by hexokinase (Hxk)/glucokinase (Gk) and phosphate transfer from phosphoenolpyruvate to $\mathrm{ADP}$ during the production of pyruvate by pyruvate kinase (Pki), may also play a role in the regulation of the metabolic flux in glycolysis (Yang et al., 2017b). Recently, we tested Hxk, Pfk and Pki, as well as the glucose transporter $\mathrm{MstC}$ in the cexA-disruption strain mentioned above. Individual overexpression of these genes increased malic acid accumulation, and the co-overexpression of these four genes significantly improved the malic acid yield on glucose from 1.27 to $1.64 \mathrm{~mol} / \mathrm{mol}$ (Xu et al., 2020).

\section{CONCLUSIONS AND PERSPECTIVES}

Metabolic engineering has been developed into a powerful tool for understanding the mechanism of malic acid biosynthesis, and also greatly promoted the progresses of engineering in E. coli, yeasts, and filamentous fungi for malic acid production. Since bacteria such as E. coli are generally not good natural malic acid production strains and also accumulate many by-products such as acetate, lactate, ethanol and formate, introduction of heterologous genes or pathways to reconstruct biosynthesis pathways with combinational deletion of genes from competing pathways is the most common strategy. While some yeasts and filamentous fungi can naturally produce high amounts of malic acid, combined enhancement of their native synthetic pathways, generally the rTCA pathway, with increased export of malic acid from the cell could dramatically improve the product titer. Efficient strategies for eliminating by-products such as succinic and citric acid, as well as the enhancement of relevant 
metabolic fluxes have also been exploited to increase the malic acid yield in A. niger, A. oryzae and M. thermophila (Li et al., 2019; Xu et al., 2019; Liu et al., 2018). Compared with S. cerevisiae and prokaryotes, the malic acid titers of filamentous fungi were usually higher (Table 1). Therefore, filamentous fungi are considered the most promising host strains for the microbial fermentation of malic acid. Notably, the engineered A. niger S575 with GRAS status produced the highest malic acid titer reported to date, and after elimination of the by-product citric acid and enhancement of the main metabolic flux, the yield of malic acid from glucose was further improved. The elimination of major byproducts can significantly decrease the cost of downstream processing by simplifying separation and purification. Additionally, $50 \%$ of the total cost is used for the separation and extraction process of malic acid produced by microbal fermentation (Dai Z. et al., 2018). Nevertheless, the industrial success of biosynthesis is ultimately based on rapid and economical conversion of substrates into target products, so from the view of industrialization, the next reconstructive emphasis will concern on: 1) shortening the fermentation period, 2) identifying the limiting factors for the efficient use of cheap carbon feedstocks, 3) exploring the regulatory factors of L-malate synthesis pathway to improve production efficiency, 4) reducing by-product synthesis to increase L-malate yield and reduce the costs of downstream separation and extraction.

Low-cost sugar feedstocks are preferred for large scale fermentation for increase of profit margin. The price of raw materials accounts for a large proportion of the total production cost in industrial fermentation processes. However, the substrate used for microbial fermentation of malic acid is mostly the relatively expensive glucose. Accordingly, the selection of more economical renewable feedstocks for malic acid production, such as lignocellulosic biomass from agricultural waste or crude glycerol from the biodiesel industry, has received increasing attention. Biotechnological processes have shown great potential to utilize these cheap feedstocks for malic acid production (Zambanini et al.,

\section{REFERENCES}

Abe, S., Furuya, A., Saito, T., and Takayama, K. (1962). Method of Producing L-Malic Acid by Fermentation. U.S. Patent 3,063,910.

Arts, E., Kubicek, C. P., and Röhr, M. (1987). Regulation of Phosphofructokinase from Aspergillus niger: Effect of Fructose 2,6-bisphosphate on the Action of Citrate, Ammonium Ions and AMP. Microbiology 133, 1195-1199. doi:10.1099/ 00221287-133-5-1195

Battat, E., Peleg, Y., Bercovitz, A., Rokem, J. S., and Goldberg, I. (1991). Optimization ofL-Malic Acid Production byAspergillus Flavus in a Stirred Fermentor. Biotechnol. Bioeng. 37, 1108-1116. doi:10.1002/bit.260371117

Bercovitz, A., Peleg, Y., Battat, E., Rokem, J. S., and Goldberg, I. (1990). Localization of Pyruvate Carboxylase in Organic Acid-Producing Aspergillus Strains. Appl. Environ. Microbiol. 56, 1594-1597. doi:10.1128/aem.56.6.1594-1597.1990

Brown, S. H., Bashkirova, L., Berka, R., Chandler, T., Doty, T., McCall, K., et al. (2013). Metabolic Engineering of Aspergillus oryzae NRRL 3488 for Increased Production of L-Malic Acid. Appl. Microbiol. Biotechnol. 97, 8903-8912. doi:10.1007/s00253-013-5132-2

Cao, W., Yan, L., Li, M., Liu, X., Xu, Y., Xie, Z., et al. (2020). Identification and Engineering a C4-Dicarboxylate Transporter for Improvement of Malic Acid Production in Aspergillus niger. Appl. Microbiol. Biotechnol. 104, 9773-9783. doi:10.1007/s00253-020-10932-1 2016b; Li et al., 2019). Metabolically engineering the most promising strains to develop versatile processes which can be adapted to cost-effective feedstocks may be another important subject of future research.

In all the current processes of microbial fermentation for malic acid production, large amounts of $\mathrm{CaCO}_{3}$ must be added as a neutralizing agent to keep the culture $\mathrm{pH}$ constant at around 6.5. As a consequence, the fermentation end-product is calcium malate formed in the bioreactor, which requires cost-intensive acidification and precipitation for conversion into pure malic acid during downstream processing. Systems biology or the latest genome-scale metabolic models can provide solutions to complex metabolic engineering goals of industrial importance (Upton et al., 2020), and further genetic engineering of malic acid-producing strains of Aspergillus, which have extremely high natural acid tolerance, to produce malic acid at low $\mathrm{pH}$ values would be a promising approach to avoid the excessive addition of neutralizing agents.

\section{AUTHOR CONTRIBUTIONS}

ZW and YX did literature survey and wrote initial draft. QX and WC reviewed and corrected the draft manuscript. $\mathrm{HH}$ and $\mathrm{HL}$ supervised the project and finalized the manuscript. All authors have made a direct intellectual contribution to the work and approved it for publication.

\section{FUNDING}

This work was supported by the National Key Research and Development Program of China (2021YFC2100700), Tianjin Synthetic Biotechnology Innovation Capacity Improvement Project (TSBICIP-KJGG-006) and the Natural Science Fund for Colleges and Universities in Jiangsu Province (19KJB530011, 19KJB530012).

Capuder, M., Šolar, T., Benčina, M., and Legiša, M. (2009). Highly Active, Citrate Inhibition Resistant Form of Aspergillus niger 6-Phosphofructo-1-Kinase Encoded by a Modified $p f k A$ Gene. J. Biotechnol. 144, 51-57. doi:10.1016/ j.jbiotec.2009.04.004

Chen, X., Wang, Y., Dong, X., Hu, G., and Liu, L. (2017). Engineering rTCA Pathway and C4-Dicarboxylate Transporter for L-Malic Acid Production. Appl. Microbiol. Biotechnol. 101, 4041-4052. doi:10.1007/s00253-017-8141-8

Chen, X., Xu, G., Xu, N., Zou, W., Zhu, P., Liu, L., et al. (2013). Metabolic Engineering of Torulopsis Glabrata for Malate Production. Metab. Eng. 19, 10-16. doi:10.1016/j.ymben.2013.05.002

Chen, Y., Banerjee, D., Mukhopadhyay, A., and Petzold, C. J. (2020). Systems and Synthetic Biology Tools for Advanced Bioproduction Hosts. Curr. Opin. Biotechnol. 64, 101-109. doi:10.1016/j.copbio.2019.12.007

Chi, Z., Wang, Z.-P., Wang, G.-Y., Khan, I., and Chi, Z.-M. (2014). Microbial Biosynthesis and Secretion Ofl-Malic Acid and its Applications. Crit. Rev. Biotechnol. 36, 99-107. doi:10.3109/07388551.2014.924474

Chibata, I., Tosa, T., Yamamoto, K., and Takata, I. (1987). [41] Production of L-Malic Acid by Immobilized Microbial Cells. Methods Enzymol. 136, 455-463. doi:10.1016/S0076-6879(87)36043-4

Choi, S. Y., Park, S. J., Kim, W. J., Yang, J. E., Lee, H., Shin, J., et al. (2016). One-step Fermentative Production of Poly(lactate-Co-Glycolate) from Carbohydrates in Escherichia coli. Nat. Biotechnol. 34, 435-440. doi:10.1038/nbt.3485 
Dai, Z., Zhou, H., Zhang, S., Gu, H., Yang, Q., Zhang, W., et al. (2018). Current advance in Biological Production of Malic Acid Using Wild Type and Metabolic Engineered Strains. Bioresour. Tech. 258, 345-353. doi:10.1016/ j.biortech.2018.03.001

Darbani, B., Stovicek, V., van der Hoek, S. A., and Borodina, I. (2019). Engineering Energetically Efficient Transport of Dicarboxylic Acids in Yeast Saccharomyces cerevisiae. Proc. Natl. Acad. Sci. U.S.A. 116, 19415-19420. doi:10.1073/ pnas. 1900287116

Deng, Y., Mao, Y., and Zhang, X. (2016). Metabolic Engineering of a LaboratoryevolvedThermobifida fuscamuC Strain for Malic Acid Production on Cellulose and Minimal Treated Lignocellulosic Biomass. Biotechnol. Prog. 32, 14-20. doi:10.1002/btpr.2180

Ding, Q., Luo, Q., Zhou, J., Chen, X., and Liu, L. (2018). Enhancing L-Malate Production of Aspergillus oryzae FMME218-37 by Improving Inorganic Nitrogen Utilization. Appl. Microbiol. Biotechnol. 102, 8739-8751. doi:10.1007/s00253-018-9272-2

Dong, X., Chen, X., Qian, Y., Wang, Y., Wang, L., Qiao, W., et al. (2017). Metabolic Engineering of Escherichia coli W3110 to Produce L-Malate. Biotechnol. Bioeng. 114, 656-664. doi:10.1002/bit.26190

Fatichenti, F., Farris, G. A., Deiana, P., and Ceccarelli, S. (1984). Malic Acid Production and Consumption by Selected of Saccharomyces cerevisiae under Anaerobic and Aerobic Conditions. Appl. Microbiol. Biotechnol. 19, 427-429. doi:10.1007/BF00454382

Gao, C., Wang, S., Hu, G., Guo, L., Chen, X., Xu, P., et al. (2018). Engineering Escherichia coli for Malate Production by Integrating Modular Pathway Characterization with CRISPRi-Guided Multiplexed Metabolic Tuning. Biotechnol. Bioeng. 115, 661-672. doi:10.1002/bit.26486

Geiser, D. M., Pitt, J. I., and Taylor, J. W. (1998). Cryptic Speciation and Recombination in the Aflatoxin-Producing Fungus Aspergillus flavus. Proc. Natl. Acad. Sci. 95, 388-393. doi:10.1073/pnas.95.1.388

Geiser, E., Wiebach, V., Wierckx, N., and Blank, L. M. (2014). Prospecting the Biodiversity of the Fungal Family Ustilaginaceae for the Production of ValueAdded Chemicals. Fungal Biol. Biotechnol. 1, 2. doi:10.1186/s40694-014-0002-y

Goldberg, I., Rokem, J. S., and Pines, O. (2006). Organic Acids: Old Metabolites, New Themes. J. Chem. Technol. Biotechnol. 81, 1601-1611. doi:10.1002/ jctb. 1590

Grobler, J., Bauer, F., Subden, R. E., and Van Vuuren, H. J. J. (1995). Themael Gene ofSchizosaccharomyces Pombe Encodes a Permease for Malate and Other C4 Dicarboxylic Acids. Yeast 11, 1485-1491. doi:10.1002/yea.320111503

Guo, L., Zhang, F., Zhang, C., Hu, G., Gao, C., Chen, X., et al. (2018). Enhancement of Malate Production through Engineering of the Periplasmic rTCA Pathway in Escherichia coli. Biotechnol. Bioeng. 115, 1571-1580. doi:10.1002/bit.26580

Habison, A., Kubicek, C. P., and Röhr, M. (1983). Partial Purification and Regulatory Properties of Phosphofructokinase from Aspergillus niger. Biochem. J. 209, 669-676. doi:10.1042/bj2090669

Iyyappan, J., Baskar, G., Bharathiraja, B., and Saravanathamizhan, R. (2018a). Malic Acid Production from Biodiesel Derived Crude Glycerol Using Morphologically Controlled Aspergillus niger in Batch Fermentation. Bioresour. Tech. 269, 393-399. doi:10.1016/j.biortech.2018.09.002

Iyyappan, J., Baskar, G., Gnansounou, E., Pandey, A., Raaman, J. K., Bharathiraja, B., et al. (2019a). Recent Advances in Microbial Production of Malic Acid from Renewable Byproducts. Rev. Environ. Sci. Biotechnol. 18, 579-595. doi:10.1007/ s11157-019-09503-2

Iyyappan, J., Bharathiraja, B., Baskar, G., Jayamuthunagai, J., Barathkumar, S., and Anna shiny, R. (2018b). Malic Acid Production by Chemically Induced Aspergillus niger MTCC 281 Mutant from Crude Glycerol. Bioresour. Tech. 251, 264-267. doi:10.1016/j.biortech.2017.12.055

Iyyappan, J., Bharathiraja, B., Baskar, G., and Kamalanaban, E. (2019b). Process Optimization and Kinetic Analysis of Malic Acid Production from Crude Glycerol Using Aspergillus niger. Bioresour. Tech. 281, 18-25. doi:10.1016/ j.biortech.2019.02.067

Janausch, I. G., Zientz, E., Tran, Q. H., Kröger, A., and Unden, G. (2002). C4dicarboxylate Carriers and Sensors in Bacteria. Biochim. Biophys. Acta (Bba) Bioenerg. 1553, 39-56. doi:10.1016/s0005-2728(01)00233-x

Jantama, K., Haupt, M. J., Svoronos, S. A., Zhang, X., Moore, J. C., Shanmugam, K. T., et al. (2008). Combining Metabolic Engineering and Metabolic Evolution to Develop Nonrecombinant Strains ofEscherichia Coli C that Produce Succinate and Malate. Biotechnol. Bioeng. 99, 1140-1153. doi:10.1002/bit.21694
Kawagoe, M., Hyakumura, K., Suye, S.-I., Miki, K., and Naoe, K. (1997). Application of Bubble Column Fermentors to Submerged Culture of Schizophyllum Commune for Production of L-Malic Acid. J. Ferment. Bioeng. 84, 333-336. doi:10.1016/S0922-338X(97)89254-9

Khan, I., Nazir, K., Wang, Z.-P., Liu, G.-L., and Chi, Z.-M. (2014). Calcium Malate Overproduction by Penicillium viticola 152 Using the Medium Containing Corn Steep Liquor. Appl. Microbiol. Biotechnol. 98, 1539-1546. doi:10.1007/ s00253-013-5326-7

Khan, I., Qayyum, S., Ahmed, S., Maqbool, F., Tauseef, I., Haleem, K. S., et al. (2017). Cloning and Characterization of Pyruvate Carboxylase Gene Responsible for Calcium Malate Overproduction in Penicillium viticola 152 and its Expression Analysis. Gene 605, 81-91. doi:10.1016/j.gene.2016.12.036

Knuf, C., Nookaew, I., Brown, S. H., McCulloch, M., Berry, A., and Nielsen, J. (2013). Investigation of Malic Acid Production in Aspergillus oryzae under Nitrogen Starvation Conditions. Appl. Environ. Microbiol. 79, 6050-6058. doi:10.1128/AEM.01445-13

Knuf, C., Nookaew, I., Remmers, I., Khoomrung, S., Brown, S., Berry, A., et al. (2014). Physiological Characterization of the High Malic Acid-Producing Aspergillus oryzae Strain 2103a-68. Appl. Microbiol. Biotechnol. 98, 3517-3527. doi:10.1007/s00253-013-5465-x

Kövilein, A., Kubisch, C., Cai, L., and Ochsenreither, K. (2020). Malic Acid Production from Renewables: a Review. J. Chem. Technol. Biotechnol. 95 (3), 513-526. doi:10.1002/jctb.6269

Kurgan, G., Kurgan, L., Schneider, A., Onyeabor, M., Rodriguez-Sanchez, Y., Taylor, E., et al. (2019). Identification of Major Malate export Systems in an Engineered Malate-Producing Escherichia coli Aided by Substrate Similarity Search. Appl. Microbiol. Biotechnol. 103, 9001-9011. doi:10.1007/s00253-019-10164-y

Li, J., Lin, L., Sun, T., Xu, J., Ji, J., Liu, Q., et al. (2020). Direct Production of Commodity Chemicals from Lignocellulose Using Myceliophthora Thermophila. Metab. Eng. 61, 416-426. doi:10.1016/j.ymben.2019.05.007

Li, X., Liu, Y., Yang, Y., Zhang, H., and Wang, H. (2014). High Levels of Malic Acid Production by the Bioconversion of Corn Straw Hydrolyte Using an Isolated Rhizopus Delemar Strain. Biotech. Biopro. Eng. doi:10.1007/s12257014-0047-z

Li, Q., Wu, H., Li, Z., and Ye, Q. (2016a). Enhanced Succinate Production from Glycerol by Engineered Escherichia coli Strains. Bioresour. Tech. 218, 217-223. doi:10.1016/j.biortech.2016.06.090

Li, Z., Xu, J., Jiang, T., Ge, Y., Liu, P., Zhang, M., et al. (2016b). Overexpression of Transport Proteins Improves the Production of 5-aminovalerate from L-Lysine in Escherichia coli. Sci. Rep. 6, 30884. doi:10.1038/srep30884

Liu, J., Li, J., Liu, Y., Shin, H.-D., Ledesma-Amaro, R., Du, G., et al. (2018). Synergistic Rewiring of Carbon Metabolism and Redox Metabolism in Cytoplasm and Mitochondria of Aspergillus oryzae for Increased L-Malate Production. ACS Synth. Biol. 7, 2139-2147. doi:10.1021/acssynbio.8b00130

Liu, J., Li, J., Shin, H.-D., Du, G., Chen, J., and Liu, L. (2017b). Metabolic Engineering of Aspergillus oryzae for Efficient Production of $\mathrm{L}$-malate Directly from Corn Starch. J. Biotechnol. 262, 40-46. doi:10.1016/ j.jbiotec.2017.09.021

Liu, J., Xie, Z., Shin, H.-D., Li, J., Du, G., Chen, J., et al. (2017a). Rewiring the Reductive Tricarboxylic Acid Pathway and L-Malate Transport Pathway of Aspergillus oryzae for Overproduction of L-Malate. J. Biotechnol. 253, 1-9. doi:10.1016/j.jbiotec.2017.05.011

Lumyong, S., and Tomita, F. (1993). L-malic Acid Production by an Albino Strain of Monascus Araneosus. World J. Microbiol. Biotechnol. 9, 383-384. doi:10.1007/BF00383086

Mainguet, S. E., Gronenberg, L. S., Wong, S. S., and Liao, J. C. (2013). A Reverse Glyoxylate Shunt to Build a Non-native Route from C4 to C2 in Escherichia coli. Metab. Eng. 19, 116-127. doi:10.1016/j.ymben.2013.06.004

Martinez, I., Gao, H., Bennett, G. N., and San, K.-Y. (2018). High Yield Production of Four-Carbon Dicarboxylic Acids by Metabolically Engineered Escherichia coli. J. Ind. Microbiol. Biotechnol. 45, 53-60. doi:10.1007/s10295-017-1991-3

Meek, J. S. (1975). The Determination of a Mechanism of Isomerization of Maleic Acid to Fumaric Acid. J. Chem. Educ. 52, 541-543. doi:10.1021/ ed052p541

Meijer, S., Otero, J., Olivares, R., Andersen, M. R., Olsson, L., and Nielsen, J. (2009). Overexpression of Isocitrate Lyase-Glyoxylate Bypass Influence on Metabolism in Aspergillus niger. Metab. Eng. 11, 107-116. doi:10.1016/j.ymben.2008.12.002 
Moon, S. Y., Hong, S. H., Kim, T. Y., and Lee, S. Y. (2008). Metabolic Engineering of Escherichia coli for the Production of Malic Acid. Biochem. Eng. J. 40, 312-320. doi:10.1016/j.bei.2008.01.00110.1016/j.bej.2008.01.001

Mu, L., and Wen, J. (2013). Engineered Bacillus Subtilis 168 Produces L-Malate by Heterologous Biosynthesis Pathway Construction and Lactate Dehydrogenase Deletion. World J. Microbiol. Biotechnol. 29, 33-41. doi:10.1007/s11274-012$1155-6$

Nagata, N., Nakahara, T., and Tabuchi, T. (1993). Fermentative Production of Poly( $\beta$-L-Malic Acid), a Polyelectrolytic Biopolyester, byAureobasidiumsp. Biosci. Biotechnol. Biochem. 57, 638-642. doi:10.1271/bbb.57.638

Naude, A., and Nicol, W. (2018). Malic Acid Production through the Whole-Cell Hydration of Fumaric Acid with Immobilised Rhizopus Oryzae. Biochem. Eng. J. 137, 152-161. doi:10.1016/j.bej.2018.05.022

Niu, J., Arentshorst, M., Nair, P. D. S., Dai, Z., Baker, S. E., Frisvad, J. C., et al. (2016). Identification of a Classical Mutant in the Industrial Host Aspergillus niger by Systems Genetics: LaeA Is Required for Citric Acid Production and Regulates the Formation of Some Secondary Metabolites. G3-genes Genom. Genet. 6, 193-204. doi:10.1534/g3.115.024067

Ochsenreither, K., Fischer, C., Neumann, A., and Syldatk, C. (2014). Process Characterization and Influence of Alternative Carbon Sources and Carbon-ToNitrogen Ratio on Organic Acid Production by Aspergillus oryzae DSM1863. Appl. Microbiol. Biotechnol. 98, 5449-5460. doi:10.1007/s00253-014-5614-x

Park, S. H., Kim, H. U., Kim, T. Y., Park, J. S., Kim, S.-S., and Lee, S. Y. (2014). Metabolic Engineering of Corynebacterium Glutamicum for L-Arginine Production. Nat. Commun. 5, 4618. doi:10.1038/ncomms5618

Peksel, N. Torres, J. Liu, G. Junea, A., Torres, N. V., Liu, J., Juneau, G., and Kubicek, C. P. (2002). 13 C-NMR Analysis of Glucose Metabolism during Citric Acid Production by Aspergillus niger. Appl. Microbiol. Biotechnol. 58, 157-163. doi:10.1007/s00253-001-0839-x

Peleg, Y., Stieglitz, B., Kesse, 1. M., and Goldberg, I. (1988). Malic Acid Accumulation by Aspergillus flavus. Appl. Microbiol. Biotechnol. 28, 69-75. doi:10.1007/BF00250501

Pines, O., Even-Ram, S., Elnathan, N., Battat, E., Aharonov, O., Gibson, D., et al. (1996). The Cytosolic Pathway of L-Malic Acid Synthesis in Saccharomyces cerevisiae: the Role of Fumarase. Appl. Microbiol. Biotechnol. 46, 393-399. doi:10.1007/BF00166235

Pines, O., Shemesh, S., Battat, E., and Goldberg, I. (1997). Overexpression of Cytosolic Malate Dehydrogenase (MDH2) Causes Overproduction of Specific Organic Acids in Saccharomyces cerevisiae. Appl. Microbiol. Biotechnol. 48, 248-255. doi:10.1007/s002530051046

Ruijter, G. J. G., Panneman, H., and Visser, J. (1997). Overexpression of Phosphofructokinase and Pyruvate Kinase in Citric Acid-Producing Aspergillus niger. Biochim. Biophys. Acta (Bba) - Gen. Subjects 1334, 317-326. doi:10.1016/s0304-4165(96)00110-9

Sauer, M., Porro, D., Mattanovich, D., and Branduardi, P. (2008). Microbial Production of Organic Acids: Expanding the Markets. Trends Biotechnol. 26, 100-108. doi:10.1016/j.tibtech.2007.11.006

Schwartz, H., and Radler, F. (1988). Formation of L(-)malate by Saccharomyces cerevisiae during Fermentation. Appl. Microbiol. Biotechnol. 27, 553-560. doi:10.1007/BF00451631

Somasundaram, S., Eom, G. T., and Hong, S. H. (2018). Efficient Malic Acid Production in Escherichia coli Using a Synthetic Scaffold Protein Complex. Appl. Biochem. Biotechnol. 184, 1308-1318. doi:10.1007/s12010-017-2629-7

Steffan, J. S., and McAlister-Henn, L. (1992). Isolation and Characterization of the Yeast Gene Encoding the MDH3 Isozyme of Malate Dehydrogenase. J. Biol. Chem. 267, 24708-24715. doi:10.1016/s0021-9258(18)35822-8

Steiger, M. G., Rassinger, A., Mattanovich, D., and Sauer, M. (2019). Engineering of the Citrate Exporter Protein Enables High Citric Acid Production in Aspergillus niger. Metab. Eng. 52, 224-231. doi:10.1016/j.ymben.2018.12.004

Taing, O., and Taing, K. (2006). Production of Malic and Succinic Acids by SugarTolerant Yeast Zygosaccharomyces Rouxii. Eur. Food Res. Technol. 224, 343-347. doi:10.1007/s00217-006-0323-z

Thakker, C., Martínez, I., Li, W., San, K.-Y., and Bennett, G. N. (2015). Metabolic Engineering of Carbon and Redox Flow in the Production of Small Organic Acids. J. Ind. Microbiol. Biotechnol. 42, 403-422. doi:10.1007/s10295-014-1560-y

Trichez, D., Auriol, C., Baylac, A., Irague, R., Dressaire, C., Carnicer-Heras, M., et al. (2018). Engineering of Escherichia coli for Krebs Cycle-dependent Production of Malic Acid. Microb. Cell Fact. 17, 113. doi:10.1186/s12934-018-0959-y
Upton, D. J., McQueen-Mason, S. J., and Wood, A. J. (2020). In Silico evolution of Aspergillus niger Organic Acid Production Suggests Strategies for Switching Acid Output. Biotechnol. Biofuels 13, 27. doi:10.1186/s13068-020-01678-z

Valentini, M., Storelli, N., and Lapouge, K. (2011). Identification of C 4 Dicarboxylate Transport Systems in Pseudomonas aeruginosaPAO1. J. Bacteriol. 193, 4307-4316. doi:10.1128/JB.05074-11

van Maris, A. J. A., Geertman, J.-M. A., Vermeulen, A., Groothuizen, M. K., Winkler, A. A., Piper, M. D. W., et al. (2004). Directed Evolution of Pyruvate Decarboxylase-Negative Saccharomyces cerevisiae, Yielding a C 2 -Independent, Glucose-Tolerant, and Pyruvate-Hyperproducing Yeast. Appl. Environ. Microbiol. 70, 159-166. doi:10.1128/aem.70.1.159-166.2004

van Urk, H., Schipper, D., Breedveld, G. J., Mak, P. R., Alexander Scheffers, W., and van Dijken, J. P. (1989). Localization and Kinetics of Pyruvate-Metabolizing Enzymes in Relation to Aerobic Alcoholic Fermentation in Saccharomyces cerevisiae CBS 8066 and Candida Utilis CBS 621. Biochim. Biophys. Acta (Bba) - Gen. Subjects 992, 78-86. doi:10.1016/0304-4165(89)90053-6

Wang, Z.-P., Wang, G.-Y., Khan, I., and Chi, Z.-M. (2013). High-level Production of Calcium Malate from Glucose by Penicillium sclerotiorum K302. Bioresour. Tech. 143, 674-677. doi:10.1016/j.biortech.2013.06.051

Werpy, T., and Petersen, G. (2004). Top Value Added Chemicals from Biomass: Volume I-Results of Screening for Potential Candidates from Sugars and Synthesis Gas. No. DOE/GO-102004-1992. Golden, CO: National Renewable Energy Lab. doi:10.2172/15008859

West, T. P. (2015). Fungal Biotransformation of Crude Glycerol into Malic Acid. Z. Für Naturforsch. C 70, 165-167. doi:10.1515/znc-2015-0115

West, T. P. (2011). Malic Acid Production from Thin Stillage by Aspergillus Species. Biotechnol. Lett. 33, 2463-2467. doi:10.1007/s10529-011-0720-7

Xu, Y., Shan, L., Zhou, Y., Xie, Z., Ball, A. S., Cao, W., et al. (2019). Development of a CreloxP-Based Genetic System in Aspergillus niger ATCC1015 and its Application to Construction of Efficient Organic Acid-Producing Cell Factories. Appl. Microbiol. Biotechnol. 103, 8105-8114. doi:10.1007/s00253-019-10054-3

Xu, Y., Zhou, Y., Cao, W., and Liu, H. (2020). Improved Production of Malic Acid in Aspergillus niger by Abolishing Citric Acid Accumulation and Enhancing Glycolytic Flux. ACS Synth. Biol. 9, 1418-1425. doi:10.1021/ acssynbio.0c00096

Yang, L., Christakou, E., Vang, J., Lübeck, M., and Lübeck, P. S. (2017a). Overexpression of a C4-Dicarboxylate Transporter Is the Key for Rerouting Citric Acid to C4-Dicarboxylic Acid Production in Aspergillus carbonarius. Microb. Cell Fact. 16, 43. doi:10.1186/s12934-017-0660-6

Yang, L., Lübeck, M., and Lübeck, P. S. (2017b). Aspergillus as a Versatile Cell Factory for Organic Acid Production. Fungal Biol. Rev. 31, 33-49. doi:10.1016/j.fbr.2016.11.001

Yin, X., Li, J., Shin, H. D., Du, G., Liu, L., and Chen, J. (2015). Metabolic Engineering in the Biotechnological Production of Organic Acids in the Tricarboxylic Acid Cycle of Microorganisms: Advances and Prospects. Biotechnol. Adv. 33, 830-841. doi:10.1016/j.biotechadv.2015.04.006

Zambanini, T., Hosseinpour Tehrani, H., Geiser, E., Sonntag, C. K., Buescher, J. M., Meurer, G., et al. (2017). Metabolic Engineering of Ustilago Trichophora TZ1 for Improved Malic Acid Production. Metab. Eng. Commun. 4, 12-21. doi:10.1016/j.meteno.2017.01.002

Zambanini, T., Kleineberg, W., Sarikaya, E., Buescher, J. M., Meurer, G., Wierckx, N., et al. (2016a). Enhanced Malic Acid Production from Glycerol with HighCell Density Ustilago Trichophora TZ1 Cultivations. Biotechnol. Biofuels 9, 135. doi:10.1186/s13068-016-0553-7

Zambanini, T., Sarikaya, E., Kleineberg, W., Buescher, J. M., Meurer, G., Wierckx, N., et al. (2016b). Efficient Malic Acid Production from Glycerol with Ustilago Trichophora TZ1. Biotechnol. Biofuels 9, 67. doi:10.1186/ s13068-016-0483-4

Zelle, R. M., de Hulster, E., Kloezen, W., Pronk, J. T., and van Maris, A. J. A. (2010). Key Process Conditions for Production of C 4 Dicarboxylic Acids in Bioreactor Batch Cultures of an Engineered Saccharomyces cerevisiae Strain. Appl. Environ. Microbiol. 76, 744-750. doi:10.1128/AEM.02396-09

Zelle, R. M., de Hulster, E., van Winden, W. A., de Waard, P., Dijkema, C., Winkler, A. A., et al. (2008). Malic Acid Production by Saccharomyces cerevisiae : Engineering of Pyruvate Carboxylation, Oxaloacetate Reduction, and Malate Export. Appl. Environ. Microbiol. 74, 2766-2777. doi:10.1128/AEM.02591-07

Zhang, T., Ge, C., Deng, L., Tan, T., and Wang, F. (2015). C4-dicarboxylic Acid Production by Overexpressing the Reductive TCA Pathway. FEMS Microbiol. Lett. 362, 1-10. doi:10.1093/femsle/fnv052 
Zhang, X., Wang, X., Shanmugam, K. T., and Ingram, L. O. (2011). 1 -Malate Production by Metabolically Engineered Escherichia coli. Appl. Environ. Microbiol. 77, 427-434. doi:10.1128/AEM.01971-10

Zhou, L., Niu, D.-D., Tian, K.-M., Chen, X.-Z., Prior, B. A., Shen, W., et al. (2012). Genetically Switched D-Lactate Production in Escherichia coli. Metab. Eng. 14, 560-568. doi:10.1016/j.ymben.2012.05.004

Zhu, L.-W., and Tang, Y.-J. (2017). Current Advances of Succinate Biosynthesis in Metabolically Engineered Escherichia coli. Biotechnol. Adv. 35, 1040-1048. doi:10.1016/j.biotechadv.2017.09.007

Zou, X., Wang, Y., Tu, G., Zan, Z., and Wu, X. (2015). Adaptation and Transcriptome Analysis of Aureobasidium Pullulans in Corncob Hydrolysate for Increased Inhibitor Tolerance to Malic Acid Production. PLoS One 10, e0121416. doi:10.1371/journal.pone.0121416

Zou, X., Zhou, Y., and Yang, S.-T. (2013). Production of Polymalic Acid and Malic Acid byAureobasidium Pullulansfermentation and Acid Hydrolysis. Biotechnol. Bioeng. 110, 2105-2113. doi:10.1002/ bit. 24876
Conflict of Interest: The authors declare that the research was conducted in the absence of any commercial or financial relationships that could be construed as a potential conflict of interest.

Publisher's Note: All claims expressed in this article are solely those of the authors and do not necessarily represent those of their affiliated organizations, or those of the publisher, the editors and the reviewers. Any product that may be evaluated in this article, or claim that may be made by its manufacturer, is not guaranteed or endorsed by the publisher.

Copyright (c) $2021 \mathrm{Wei}, \mathrm{Xu}, \mathrm{Xu}$, Cao, Huang and Liu. This is an open-access article distributed under the terms of the Creative Commons Attribution License (CC BY). The use, distribution or reproduction in other forums is permitted, provided the original author(s) and the copyright owner(s) are credited and that the original publication in this journal is cited, in accordance with accepted academic practice. No use, distribution or reproduction is permitted which does not comply with these terms. 